\title{
Discretionary Authority and Prioritizing in Government Agencies*
}

\author{
Maarten Pieter Schinkel† Lukáš Tóth ${ }^{\ddagger}$ and Jan Tuinstra ${ }^{\S}$
}

December 2014

\begin{abstract}
Government agencies typically have a certain freedom to choose among different possible courses of action. This paper studies agency decision-making on priorities in a principal-agent framework with multi-tasking. The agency head (the principal) has discretion over part of the agency's budget to incentivize his staff (agents) in the pick-up of cases. The head is concerned with society's benefits from the agency's overall performance, but also with the organization's public image as formed from pursuing high-profile cases and various non-case specific activities. Based on their talent and the contracts offered by the head, staff officials choose which type of task to pursue: complex major, yet difficult to complete cases with an uncertain outcome, or basic minor and simple cases with a high probability of success. The size of the agency's discretionary budget influences not only the scale, but also the type of tasks it will engage in. Social welfare is non-monotonic and discontinuous in the agency's budget. Small changes in the budget may cause extensive restructuring from major to minor tasks, or vice versa. A budget cut can increase welfare more than too little extra budget would. For lower binding budgets, the head continues to suboptimally incentivize work on complex tasks, when the agency should have shifted down to simpler tasks. In determining the discretionary space of the agency head, the budget-setter can limit the extraction of resources, but thereby also reduces the benefits from the head's superior information on how to incentivize the officials. Antitrust authorities serve as one illustration of policy implications for institutional design, including optimal budgetting and agency mergers.
\end{abstract}

JEL-codes: D02, L44, M52

Keywords: Government agency, discretion, budget, enforcement priorities, antitrust

*We thank Alberto Alesina, Gergely Csorba, Joseph Harrington, Morten Hviid, William Kovacic, John Kwoka, Daniel Sokol, Joao Vareda, Bauke Visser and conference participants at CLEEN 2013, CRESSE 2013, EARIE 2013, "The Reform of Competition and Regulatory Authorities in Europe," University of Barcelona, 2013, and the Haifa-Loyola joint workshop 2014 at Haifa University for comments to earlier versions of this paper. All remaining errors are ours.

$\dagger$ Amsterdam School of Economics and ACLE, University of Amsterdam. Correspondence at: Plantage Muidergracht 12, 1018TV Amsterdam, The Netherlands. E-mail: m.p.schinkel@uva.nl.

$¥$ Amsterdam School of Economics and ACLE, University of Amsterdam.

$\S$ Amsterdam School of Economics and CeNDEF, University of Amsterdam. 


\section{Introduction}

Government agencies are organizations in the machinery of government with a certain amount of autonomy and independence from political influence in the execution of their functions in oversight and administration. Examples are central banks, intelligence agencies, internal revenue services, antitrust authorities, public prosecutors, energy regulators and gambling control boards. The laws these institutions enforce typically leave them considerable freedom to choose among different possible courses of action according to their own judgment. Principally tasked with decision making in specific cases, government agencies have varying levels of discretion over how to prioritize potential matters to pursue, how to conduct investigations, and what remedies to impose upon a finding of a breach of law. The agencies also have other, non-case specific concerns of impression management, that is, self-presentation through professional communication and public relations directed at forming the organization's public image. To a government agency, image is particularly important, as their tasks, be it controlling inflation, terrorism, money laundering, cartels or gambling schemes, by their nature often are enigmatic to the general public. Impression management helps secure public support for the agency's stately goals and tasks - and so indirectly also its future budget.

Like all organizations, government agencies are networks of principal-agent relationships, and therefore riddled with agency issues that influence the allocation of resources over various tasks. Economic theory has long studied goal mismatches and incentive-provision schemes in principal-agent relationships within firms. ${ }^{1}$ While there have been calls for the introduction of incentive contracts into public organizations as well, the canonical principal-agent model is not directly transferable to non-profit organizations. ${ }^{2}$ Government agencies differ from profit-maximizing firms in important aspects, including external (political) resource assignment and difficult measurement of output. These characteristics allow for other civil servant incentives than just serving social welfare to take hold, among which mission-motivation, empire-building and conformity are known to induce suboptimal spending, bureaucratic slack and promotion of third-party interest. ${ }^{3}$

In this paper we study in an agency-context how variations in its available resources can qualitatively change the range of activities the government agency will engage in, and how this will affect welfare. In a principal-agent model with multi-tasking, the agency has a two-level organizational structure. The head of the agency (principal) is concerned with society's benefit from the agency's overall performance, but also with impression management. The agency's employed staff of officials (agents) can choose, individually or as a team with some autonomy, from various types of activities. The tasks vary in their expertise requirements and yield of social welfare gains upon completion, the probability of which is a function of staff effort and complexity. The officials are all permanently employed at a fixed wage, but the head has discretion over part of the agency's budget to offer additional rewards to

\footnotetext{
${ }^{1}$ See Prendergast (1999), Laffont \& Martimort (2002) and Lazear (2009).

${ }^{2}$ See Barzelay (2001).

${ }^{3}$ See Niskanen (1968), Peltzman (1976), Wilson (1991) and Leaver (2009).
} 
further incentivize his staff. These variable contracts can contain explicit incentive pay, but typically also the value of future career perspectives, in- and outside the agency, schooling opportunities, or tertiary benefits officials enjoy, such as participation in the agency's international network, research projects, summer courses or conferences abroad. Depending on the contract offered, the agency officials either pursue the more demanding and complex high-profile cases, or opt to do simpler basic tasks. The head extracts the budget residue that ends up not being used as rewards for the staff's activities for other purposes, which typically do not have comparable social benefits. This residue decreases both in the size of the rewards and in the probability of the tasks being completed successfully.

We identify how under these circumstances the size of the head's discretionary budget qualitatively affects the type of activities a government agency will perform. Small changes in the budget can have drastic consequences for society's benefits from agency performance. Depending on the institution's status, discretionary budget changes over certain thresholds can cause extensive restructuring, both away from and towards activities that require more expertise and yield a major outcome. Social welfare is non-monotonic and discontinuous in the budget, as a result, so that at a jump discontinuity an infinitesimal budget cut may lead to a substantial increase in welfare, beyond the direct fund savings. At other budget levels, however, more discretionary spending increases welfare. For lower binding budgets, for example, the head sub-optimally incentivizes its staff to work on complex tasks for too long, while the agency should already have shifted down to simpler tasks that fit the limited budget. These insights underline the importance of socially optimal budgeting for government agencies. They also reveal how institutional design and budget assignments can become a control tool in the arsenal of a government pursuing political goals or promoting third-party interests against the agency's public tasks.

Our approach adds to the literature on contracting in government agencies by considering both optimal and feasible agency choice of task and performance with a given budget constraint and a multilevel hierarchy. The economic literature on governmental organization has predominantly focused on political control of government agencies, as in Macey (1992), incentives created by sharing regulatory rights between several regulatory bodies, as in Martimort (1996), and regulatory competition or collusion with separation of powers, as in Tirole (1986) and Laffont \& Martimort (1999).

We set up the objective of the agency head as a combination of social benefits and self-interest. Niskanen (1968) points at the incentives of bureaucrats for self-interested budget maximization and empire-building. ${ }^{4}$ Kreps (1997), Murdock (2002) and Benabou \& Tirole (2003) endogenize intrinsic motivation, particularly in public services and nonprofit organizations. Francois (2000, 2003) stress the importance in these institutions of mission-motivation (a desire to promote the agency's goals) and warm-glow utility (a desire for positive appraisal). Dewatripont et al. (1999) derive implications for the optimal incentive provisions when civil servants are largely driven by career concerns and missionmotivation. Alesina \& Tabellini (2007) and Alesina \& Tabellini (2008) study consequences for the type

\footnotetext{
${ }^{4}$ See also Niskanen (2007).
} 
of tasks a politician should delegate to career-concerned bureaucrats, if the agency head has either bureaucratic or political concerns. Makris (2009) shows, in an analysis of the effect of budget changes by a principal on a single mission-motivated agent, that the application of standard incentive contracts to government agencies may lead to a suboptimal provision of public services.

Our model provides a formal context to arguments put forward in an emerging legal and public administration literature on institutional design. Studying antitrust authorities, Hyman \& Kovacic (2013) stress a need for "engineering" strategies for the organization of government. ${ }^{5}$ They point at resource allocation as one key element of government agency functioning and observe that:

"[..] to do multiple things well requires both sufficient capacity and continuous fine-tuning of the agency's allocation of resources [..] Some areas will flourish while other will languish - even if budgets keep pace with new responsibilities." Hyman \& Kovacic (2013), p. 20.

Our analysis can shed light on how such fine-tuning may be done when the choices over agency's priorities are driven by the motivations and constraints of the actors involved.

Competition authorities, such as the U.S. Department of Justice's Antitrust Division, the Federal Trade Commission and the European Commission's Directorate General Competition fit our model well. They are visible and relatively transparent agencies. ${ }^{6}$ The U.S. and European competition law principals are generally formulated, whereas cases are specific, various and regularly novel. As a result, competition authorities have considerable discretion in enforcement, which is reflected in vast case law. ${ }^{7}$ Some secondary and tertiary incentive pay for officials, on top of fixed wages, is common in these agencies. Both across and within types of anti-competitive behavior, there is variation in expertise requirements and yield of social welfare gains upon completion of tasks. Monopolization or abuse of dominance are often harder, take longer and are more complex to prosecute successfully than collusion, which is per se illegal by object. Within the class of cartel investigations, there is a choice of resource allocation between cases that were brought to the attention of the authorities by a leniency application of a remorseful cartel member for amnesty and actively detecting the better organized cartels. The extent to which antitrust agencies should rely on the simpler leniency cases for the public good depends on staff talent, budget and the difficulty of independent discovery.

Antitrust agencies furthermore display a number of non-case specific activities. With large interests at stake, competition cases are extensively debated, both professionally and in the popular press. Kovacic et al. (2011) document that competition authority heads have concerns other than social welfare alone, including appearing "being busy", with an eye to the media and political superiors. Indeed do competition authority heads appear to value attention, giving interviews and contributing

\footnotetext{
${ }^{5}$ See also Gal (2004).

${ }^{6}$ See, for example, Baker (2003), Muris (2005), Vives (2009), Crane (2011),Kovacic et al. (2011), Kovacic \& Hyman (2012) and Hyman \& Kovacic (2013).

${ }^{7}$ See Wils (2011).
} 
regularly in conferences on landmark decisions or developments in enforcement tools. In addition, there are numerous competition policy outreach products, including such fancy ones as complete enacted movies, online games, and manga comic books. ${ }^{8}$ Kovacic and co-authors express a worry that competition authorities may be wasting resources on big good-looking cases and image, while underperforming in other tasks like suggesting legislation refinements and staff preparation for advanced enforcement. Our model of multitasking in the principal-agent setting founds these concerns.

Competition cases against known companies are sure to attract media attention right from the opening of the investigation - often even more so than from its conclusion. There are examples of zealously pursued high-profile cases that eventually ended without a forceful application of the law. Throughout the 1970's, for example, the US DoJ unsuccessfully prosecuted IBM for over ten years for violation of Section 2 of the Sherman Act, to ultimately conclude in 1982 that the case was without merit. ${ }^{9}$ In hindsight, some of the senior officials involved in the decision to pursue this case admitted other motivations than just expected social gain. ${ }^{10} \mathrm{~A}$ more recent ambitious case that ultimately inflated was around Google's alleged "search bias". After an extensive investigation, the FTC concluded that the evidence in the case was not enough to support a challenge of Google for monopolization under American Law. The chairman of the FTC at the time, Jon Leibowitz, explained so in a lengthy press conference that was broadcasted live on national television. The European Commission's parallel investigations for abuse of dominance by Google did continue, yet settlement were largely unsuccessful.

Competition authorities also illustrate how institutional design and budget assignments can fundamentally affect the political independence of government agencies. Gal (2004) observes that there are important differences in the effectiveness of competition law enforcement among developing countries, even if their legal background is similar, in large part due to the fact that

"[..] decision makers may not properly fund and structure the competition agency in order to reduce its ability to enforce law in practice." Gal (2004), p.7.

Choke of resources turning performance may be bluntly significant in developing countries, we show that the transmission is more subtly there in well-resourced agencies as well. By edging the discretionary part of the agency's budget over certain threshold values, a budget-setter can qualitatively affect the agency's task pick-up to its liking, ranging from the pursuit of complex sure failures to low hanging fruits. The budget so acts as an indirect instrument of political control over agencies.

The remainder of this paper is organized as follows. The basic model is introduced in Section 2. In Section 3, the main results under a budget restriction are presented. Welfare implications are discussed in Section 4. In Section 5, the model is extended to multiple tasks and officials. Section 6 analyzes the

\footnotetext{
${ }^{8}$ Some of these and other examples of marketing products can be found on the ICN's web-blog on "outreach".

${ }^{9}$ See Fisher et al. (1985).

${ }^{10}$ See the contribution by Fredric M. Scherer in Slottje (1999).
} 
problem of the budget-setting body, such as a Ministry or Parliament, to determine the discretionary space it wants to give the head. Section 7 concludes. The proofs are given in an appendix.

\section{A Model of Government Agency}

Consider a government agency, which has a head and officials, that can undertake several classes of activities. Each of these $n$ tasks $i \in I$, with $I=\{1, \ldots, n\}$, is characterized by a double $\left(\psi_{i}, d_{i}\right)$, where $\psi_{i} \geq 0$ represents the difficulty of task $i$ and $d_{i} \geq 0$ are the social benefits that the task yields upon successful completion. A complex high-profile case, with the potential of becoming a landmark case, has a high value of $d_{i}$, while a simple basic task has a low value. Agency officials differ in their skills, knowledge and talent level, captured by parameter $\theta \in[0,1]$, which is known both to them and to the head. ${ }^{11}$ The agency is assigned a budget, which consist of two components. A generic part of the budget pays for such costs as employing the head and the officials on fixed wage contracts for regular work, support staff, overhead for facilities, and other expenses. An additional part $D$ of the budget is at the head's sole discretion. He can use it for motivational rewards for his officials to take on additional tasks, or for impression management of his agency's public image.

The agency's organizational structure is as follows. The agency head (principal) offers an upfront take-it-of-leave-it contract to each official, or case-handling team of officials (agent), who subsequently undertake the actual tasks. In the following, we refer to the decision making agent as "the official". A contract is a list of rewards for completing the tasks. After both the head and the official learn whether the task that the official has picked up has been completed successfully, the head pays the official according to the contract terms. The residual budget part $D$, the head has available for non-case specific activities. We begin by analyzing a representative official, who decides among the performance of $n$ tasks. We then turn to the head's strategies.

In this section, we study how the restrictions on these incentive contracts affect the agency's way of prioritizing activities. Throughout this section we assume that $D$ is sufficient to finance any contract the agency head might wish to offer. In Section 3 we study the implications of a binding (discretionary) budget.

\subsection{Effort chosen by the Agency's Official}

Within the context of his contract with the agency, the official uses his professional expertise on the task set to choose which task he will try to complete in addition to his basic work load. The official cannot do more than one task at the time. In taking on a task, the official exerts effort $a \geq 0$ at a personal cost $c(a)$. His reward cannot be made conditional on his effort level directly, which is either unobservable or in-contractible by the head. Instead, the outcome is contracted. If task $i$ is successfully

\footnotetext{
${ }^{11}$ The implications of introducing asymmetric information between the head and his officials about the talent levels of the latter are discussed in Section 7.
} 
completed, the official receives the reward $R_{i} \geq 0$ specified in his contract with the agency. If no task is completed, the official's additional pay is zero. The offered contract is thus $R \in \mathbb{R}_{+, 0}^{n}$ where $R_{i} \geq 0$ for every $i$. The official can always exert no additional effort $(a=0)$ and ensure basic utility from regular work for himself. On top of his fixed income, we normalize the official's reservation utility level to zero.

Effort translates into probabilities that the task worked on will be completed, depending on talent and difficulty. If the official decides to pursue task $i$, the probability of completing that task is modeled to be

$$
p_{i}(a, \theta)=a \times \theta^{\psi_{i}},
$$

while the probability of completing any other task is zero. ${ }^{12}$

The official is risk neutral. When he decides to pursue task $i$, his expected utility is

$$
E\left[U^{O}(a, \theta)\right]=p_{i}(a, \theta) R_{i}-c(a) .
$$

The costs of his effort are set as $c(a)=\frac{1}{2} \gamma a^{2}$, where $\gamma$ is a scaling parameter. The effort costs are increasing and convex in $a$, which amounts to diminishing returns of the probability of completing a task from exerting higher effort. Note that assuming $\gamma>D$ implies that optimal effort will remain in the interval $[0,1)$, since even if the budget is fully spent on one reward, for instance $R_{i}=D$, under $\gamma>D$ for activity $a \geq 1$ marginal costs of the official's effort $\left(\frac{\partial c}{\partial a} \geq \gamma\right)$ will be higher than marginal benefits $\left(\frac{\partial p_{i}(a, \theta)}{\partial a} R_{i}<D\right)$. In other words, if $\gamma>D$, the agency never has enough money to pay the official to exert effort $a=1$ or more. ${ }^{13}$

For a given talent level $\theta$, the official chooses both which task to undertake and the effort he will make towards its completion, leaving the probability of obtaining a reward for completing the other tasks at zero. The official's payoff maximization problem can thus be written as

$$
\max _{i \in I}\left\{\max _{a}\left(\theta^{\psi_{i}} a R_{i}-\frac{1}{2} \gamma a^{2}\right)\right\}
$$

which returns a simple rule for the official's choice of task to take up.

Lemma 1. Given a contract $R \in \mathbb{R}_{+, 0}^{n}$, an official with talent level $\theta$ will undertake the task with the highest value of

\footnotetext{
${ }^{12}$ Note that the probabilities of tasks' completion are not additively separable in $\theta$ and $\psi_{i}$, so that the budget values at which the agency switches among tasks to perform under binding resource constraints in the latter chapters depend also on the talent level of the official. Results are not qualitatively different with different specifications of the probability of task completion, as long as it is increasing in $\theta$ and decreasing in $\psi_{i}$.

${ }^{13}$ In most situations, only lower values of $\gamma$ are needed to keep the official's effort and the probability of task completion in $[0,1)$. The assumption $\gamma>D$ ensures this for any values of the remaining parameters and is unnecessarily strong, for instance in cases when the agency head does not want to offer the full budget as a reward for one task. The assumption will be relaxed in some numerical examples in the text.
} 


$$
\theta^{\psi_{i}} R_{i}
$$

Moreover, under the official's optimal choices of effort, the probabilities of task completion will be:

$$
p_{i}=\frac{\theta^{2 \psi_{i}} R_{i}}{\gamma} \text { and } \forall j \neq i: p_{j}=0,
$$

if the official chooses to work on task $i$.

Proof. See Appendix.

\subsection{Contracts offered by the Agency's Head}

The agency head adds value to the governance of his institution by using the full information he has about the official's talent $\theta$ to set tailored rewards to make the official take up suitable tasks. The head does so by considering the expected benefits that the agency's activities bring to society directly, but also the value of self-presentation through impression management. We formalize the latter in two different ways. First, the head derives utility just from opening cases, in particular high-profile cases that will generate a lot of exposure, independent of the question whether they will ultimately be successful or not. Driven by political pressures or career concerns, the head's discounting of the probability of success may reflect that such cases possibly run longer than the head's term in office, so that it will be his successor, not him, who will have to see these cases through. Second, the head values any residual budget that is not spent on paying rewards. He can use this residual budget for non-case specific activities that will put him and his agency in the professional and general public eye, such as giving informal opinions or speeches, appearing in the media, and marketing. The residual budget is assumed to be fully spent on such non-case specific activities. We assume that the social welfare gains from handling cases is different from comparable gains generated by impression management spending.

The head is risk neutral. His expected utility when employing the representative official performing task $i$ is

$$
E\left[U^{H}\right]=p_{i} d_{i}+\phi d_{i}+V\left(D-p_{i} R_{i}\right)
$$

The product $p_{i} d_{i}$ is society's expected benefit from the agency's overall activity. The parameter $\phi \in[0,+\infty)$ captures the head's instantaneous incentive to open a high-profile case. In addition, the head values spending the residual budget, being the difference between the budget $D$ and the expected payment to the official $p_{i} R_{i}$, as compared to the agency's performance by parameter $V \in[0,+\infty) .{ }^{14}$

If $V=0$, all budget is offered as a reward for successfully completing cases, yet in expectations there is still a nonzero budget residue available for impression management spending. The higher

\footnotetext{
${ }^{14}$ This is similar to the setup in Makris (2009).
} 
$V$, the higher the head's tendency to channel funds away from rewarding tasks. ${ }^{15}$ Note that $V$ can capture a number of concerns the head may have, including his intrinsic motivation and personal preferences, the way in which he is evaluated by his superiors, in terms of monetary rewards, future (political) career prospects, and budget appropriation, combined with the workplace culture and the institutional system of controls in which he operates. The extent to which the head is monitored depends in large part on whether there exist informative measures of the agency's performance. Often, such measures will be noisy. The value of $V$ need not be constant over time. While instructions and the administrative procedures of an agency are in principle subject to change by government, our setup introduces replacing the agency head as an instrument of change.

Given his incentives, and knowing the agency official's optimal response, the head solves

$$
\begin{gathered}
\max _{i \in I}\left\{\max _{R_{i}}\left(\frac{\theta^{2 \psi_{i}} R_{i}}{\gamma} d_{i}+\phi d_{i}+V\left(D-\frac{\theta^{2 \psi_{i}} R_{i}^{2}}{\gamma}\right)\right)\right\} \\
\text { s.t. } R_{i} \leq D \forall i \in I .
\end{gathered}
$$

Under the assumption that any contract is affordable in the agency budget, this leads to the following simple optimal rule for the head.

Lemma 2. If the agency's budget is non-binding, by setting the appropriate rewards, the agency head will make the official with talent level $\theta$ pick up the task with the highest value of

$$
Q_{i}=\frac{\left(\theta^{\psi_{i}} d_{i}\right)^{2}}{4 V \gamma}+\phi d_{i}+V D
$$

and offer him a contract (superscript 'u' for unconstrained):

$$
R_{i}^{u}=\frac{d_{i}}{2 V} ; \forall j \neq i: R_{j}=I C C_{j},
$$

where $i$ is the task for which (2) is highest and $I C C_{j}$ is any value that satisfies the official's incentive constraint (1). ${ }^{16}$ These contracts lead to effort levels generating probabilities of task completion

$$
p_{i}^{u}=\frac{\theta^{2 \psi_{i}} d_{i}}{2 \gamma V} ; \forall j \neq i: p_{j}=0
$$

\section{Proof. See Appendix.}

\footnotetext{
${ }^{15}$ In our formal analysis, $V$ is assumed to be strictly positive to assure a solution exists, as discussed in footnote 19 . $V=0$ is discussed in later sections as a limit case that does not bring new fundamental insights.

${ }^{16}$ Note that the official's incentive constraint (1) is always satisfied by putting $I C C_{j}$ equal to zero.
} 
For analytical convenience and without loss of generality, we order all possible tasks using the head's strategy of task pickup via contract design captured in (2). Note that the head will never design a contract aimed at the official taking on a task that is hard and brings low benefits upon completion over a task with lower difficulty and higher $d_{i}$, since (2) decreases in both $\psi_{i}$ and $d_{i}$. Of all possible tasks, we can thus focus only on those that are not dominated in the sense that there is no task that would be both easier and yield higher benefits upon completion. The remaining tasks we can then order as $\left(d_{1}, \psi_{1}\right)<\left(d_{2}, \psi_{2}\right)<\ldots<\left(d_{m}, \psi_{m}\right)$, so that the most difficult task is also the most beneficial to society. ${ }^{17}$

For every task, $R_{i}^{u}$ is independent of the agency's budget. It is the reward for which the head's marginal benefit of spending an additional unit of the budget on incentivizing the official is equal to his marginal benefit of impression management spending. Note that even when resources are unlimited, there is a maximum reward, $R_{1}^{u}$, that the agency head is willing to offer to the official, as he will prefer to extract any remaining resources above that reward level, due to diminishing returns to rewards offered. This maximum reward does not depend on the talent level, but only on the head's preference for extraction $V$, since once the task choice has been made, $\theta$ influences only the probability of task completion. While more talented officials might not be offered higher rewards, in expectation they will still earn more than officials with lower $\theta$, as they can produce a higher probability of task completion with the same effort.

To obtain some further insight into the head's strategy, first consider the case when $\phi=0$, i.e. the head does not value opening cases for exposure only. The head's objective then reduces to maximizing $\theta^{\psi_{i}} d_{i}$, so that task $A$ is picked over task $B$ if $\theta^{\psi_{A}-\psi_{B}}>\frac{d_{B}}{d_{A}}$. Suppose that task $A$ is more difficult, i.e. $\left(d_{B}, \psi_{B}\right)<\left(d_{A}, \psi_{A}\right)$. The agency head then compares the ratio of $\theta^{\psi_{A}}$ and $\theta^{\psi_{B}}$, which are the terms by which the probability of the task's completion is scaled, with the factor by which completing task $B$ is less worthwhile to society than completing task $A$. When the official's talent level $\theta$ increases, the more difficult task $A$ becomes more attractive for the agency's head. ${ }^{18}$ In other words, if the agency officials are skilled enough, the agency will perform more difficult tasks. More difficult tasks will also be performed when the social benefit from completing task $A$ is sufficiently much higher than from completing the low-yielding task $B .^{19}$

The head's incentive to open high-profile cases for generating exposure $(\phi>0)$ makes the more complex tasks generally more attractive to him. It is still true that a higher level of staff talent makes the more complex cases more attractive to the agency's head, but if impression management is important enough to him (i.e., either $\phi$ or $V$ is very high), it becomes obsolete as a determinant

\footnotetext{
${ }^{17}$ Here $m \leq n$ since $n-m$ task were excluded from the set via the above mechanism.

${ }^{18} \mathrm{As}$ long as $\left(d_{B}, \psi_{B}\right)<\left(d_{A}, \psi_{A}\right)$, the agency head will prefer $A$ when the official's talent level gets closer to 1 , and $B$ when $\theta$ goes to zero with no further restrictions on the parametrization. This will no longer be the case when $\phi \neq 0$. With high enough $\phi$ the head might prefer task $A$ for any official's talent level.

${ }^{19}$ These results hold when the budget does not constrain. As will be derived later, with restrictions on the level of the rewards, it might be the head's optimal choice that the agency performs task $B$ even if the official is very skilled. See Section 3.
} 
of the agency's behavior. While without the incentive to flash high-profile cases the head's extraction plays no role in determining which task will be performed, with $\phi>0$ there is an interaction between the two motivations. Once $\phi$ or $V$ become high enough, only complex tasks will be performed by the agency, irrespective of the official's talent, since the agency head expects to be able to extract a higher budget residue thanks to a lower probability of the official successfully completing complex tasks and the higher fixed reward from exposure through the high-profile cases.

If the head does not value the mere opening of high-profile cases $(\phi=0)$, and also values the budget residue just as society values its resources $(V=1)$, the agency head would incentivize pickup of those cases that maximize the expected returns from the agency's activities minus their expected costs, $p_{i} d_{i}-p_{i} R_{i}$. That is, he would choose to reward the task with the highest $\theta^{\psi_{i}} d_{i}$. The contracts offered would then be $R_{i}^{u}=\frac{d_{i}}{2}$, which represent an optimal balance between the benefits of completing the tasks and the costs of making the official pursue them properly in terms of effort level. Do note, however, that the head still pockets the budget residue. Only if $V$ was allowed to attain its lower bound, $V=0$ (and for $\phi=0$ ), does the head allocate the budget entirely on pursuing cases. His choice of rewards would then always be $R_{i}=D .{ }^{20}$

\section{Binding Discretionary Budget and the Agency's Task Focus}

We now turn to the role of the size of the budget that is at the agency head's discretion. Note that for any value of $D$ above the head's optimal reward offer for his most preferred task, changes in $D$ only influence the head's utility through a different budget residue, not the optimal contract. However, once $D$ falls below the head's optimal reward offer for his most preferred task, the agency may come to perform different tasks under different budget constraints, leading to discontinuities in social welfare. To clarify how, we further focus on changes in the agency's performance when there are only two tasks, $A$ and $B$ with $\left(d_{B}, \psi_{B}\right)<\left(d_{A}, \psi_{A}\right)$, to choose from by the representative staff official employed by the agency's head. The main insights obtained carry over to a more general setup with multiple tasks and officials, as discussed in Section 5.

First, we can specify how the budget constraint determines which tasks the agency will perform under what conditions.

Proposition 1. For a large range of parameter values $\left(d_{A}, d_{B}, \psi_{A}, \psi_{B}, \phi, \theta, \gamma, V\right)$, there exist critical values of $D$, at which the agency abruptly changes its focus:

(i) If $Q_{B}<Q_{A}$, so that the agency focuses on the complex task $A$ when the budget does not bind, one of two possible scenarios occurs:

(i.a) For $p_{A}^{u}<p_{B}^{u}$ and sufficiently low values of $V$ and $\phi$, there are two critical budget values

\footnotetext{
${ }^{20}$ It is for this reason that we have bounded $V$ away from zero in this section for analytical convenience, since the budget is assumed to be unlimited, and the head's problem would otherwise have no solution.
} 
$D_{1}^{*}<D_{2}^{*}$ so that the agency performs task $B$ on the interval $D \in\left(D_{1}^{*}, D_{2}^{*}\right)$ and the complex task $A$ otherwise. ${ }^{21}$

(i.b) For $p_{A}^{u}>p_{B}^{u}$ or for sufficiently high values of $V$ and $\phi$, the agency keeps at task $A$ for all budget values.

(ii) If $Q_{B}>Q_{A}$, so that the agency focuses on the simpler task $B$ when the budget does not bind, there is always a critical value of $D, D_{1}^{*}$, above which the agency performs the simple task $B$ and below which it performs the more difficult task $A .^{22}$

Proof. See Appendix.

The intuition for the agency's change in focus in (i.a) from the more difficult to the simpler task (when $D$ falls below $D_{2}^{*}$ ) for an interval of binding discretionary budgets is as follows. With enough budget, the head prefers to incentivize the more complex task. Since $R_{A}^{u}>R_{B}^{u}$, as $D$ goes down from non-binding high values, this first starts influencing the probability of completing the more complex task and the utility it generates for the head. Note that as soon as the budget is binding, the head will put it all towards rewarding his designated task (should it be completed successfully), rather than spread it between the ex ante reward and the impression management activities directly. As the budget is reduced further, the head suffers two types of utility loss. One is from his inability to still sufficiently incentivize his staff to exert effort on completing the complex task to society's benefit. The other is from reduced expected budget for impression management. At some point, the head then switches from stimulating the take up of the complex task to rewarding the simple task, which requires a lower reward to complete. However, when the budget is decreased further, below the head's most preferred reward for the simple task, the probability of completion of the simple task decreases further with it, since the official exerts less effort.

As the head's fixed reward for opening a case, $\phi d_{i}$, is constant, for low enough budget values it becomes the most important determinant of the agency's performance. For those low budget levels, the head will simply prefer the tasks with the highest fixed reward just for opening them. In addition, the probability of the head actually paying the reward for completing the complex task is low, thus increasing his expected budget residue. This latter combination of effects also provides the intuition behind result (ii) in the proposition. The intermediate switch to the simpler task only happens when there is a moderate difference between the tasks' benefits, or a high difference between the tasks' difficulties, while the head is concerned primarily with social welfare. If these conditions are violated, the head cares too little about society's benefits to mind the sure ineffectiveness of trying to incentivize the complex task with too little budget. In other words, the head keeps pushing his staff to open complex high-profile cases, knowing they will most likely fail to complete them successfully, just to enjoy the exposure that such cases generate, while pocketing the unclaimed rewards for impression

\footnotetext{
${ }^{21}$ This is with the exception of $\phi=0$, for which $D_{1}^{*}=0$ and the agency performs task $B$ for all budget values below $D_{2}^{*}$.

${ }^{22}$ This is with the exception of $\phi=0$, for which $D_{1}^{*}=0$.
} 
management purposes as well.

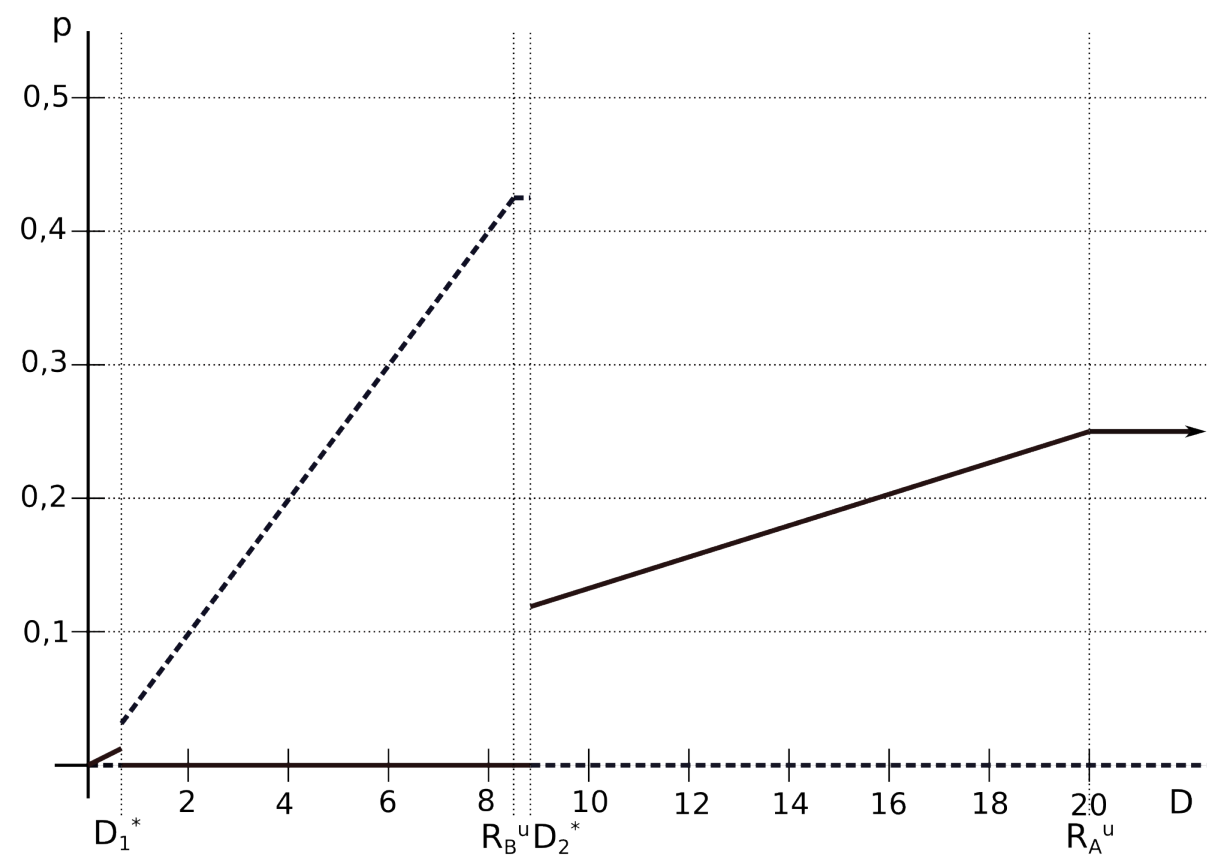

Figure 1: Probability of completing the simple task $B$ (dashed lines) and the complex task $A$ (solid lines) as a function of the available budget.

Figure 1 illustrates the effect of budget changes on the agency's case focus for one particular parametrization falling under (i.a) in Proposition 1. ${ }^{23}$ For non-binding budget values, the agency head prefers the more complex task $A$ and rewards it with a constant reward $R_{A}^{u}$. Once the budget falls below $R_{A}^{u}$, the reward offered for task $A$ becomes $D$. A linear decrease in $D$ then causes a linear decrease in the probability of completion of task $A$ via the official's behavior described in Lemma 1. With decreasing $D$, the head's utility generated by rewarding task $A$ decreases at a higher rate than the utility from rewarding task $B$, which decreases with the slope $V$ - which equals the head's marginal loss of resources to extract - up until the point $D_{2}^{*}$. Between $D_{2}^{*}$ and $D_{1}^{*}$ the head's utility is the highest for rewarding task $B$. As the budget decreases further, the fixed reward for opening a task becomes relatively more important in determining head's utility just as in (ii), and the agency's head decides to reward task $A$ at point $D_{1}^{*}$.

There is a second intuition for the existence of $D_{2}^{*}$, as the above only apply to values of $D_{2}^{*}$ in the interval $\left(R_{B}^{u}, R_{A}^{u}\right)$, while it may also fall in budget values below $R_{B}^{u} \cdot{ }^{24}$ As the available resources

\footnotetext{
${ }^{23}$ In the example in this figure, parameter values are: $\theta=0.5 ;\left(\psi_{A}, \psi_{B}\right)=(2,1) ;\left(d_{A}, d_{B}\right)=(400,170) ; \gamma=5 ; V=10$; $\phi=0.01$.

${ }^{24}$ See the conditions derived in the proof to Proposition 1.
} 
decrease, so does the head's opportunity to extract them for impression management. The lower probability of completing task $A$ - i.e. the higher probability of extracting the whole budget - is no longer as attractive for the agency's head, as the total amount of money to be had is little. Instead, the agency's performance gains relatively higher importance in determining the head's overall utility, so that he may change the contract with the official to incentivizing task $B$ below point $D_{2}^{*}$.

The less the head values impression management, the bigger will be the interval $\left(D_{1}^{*}, D_{2}^{*}\right)$. Opening complex tasks despite having insufficient funds to induce the effort to complete them successfully still generates the exposure desired by the head. In addition, a lower probability of successful completion of the complex task increases the expected left-over budget that the head can put towards non-case specific activities. If the head cares only about real cases $(V=0$ and $\phi=0)$, the agency will perform the more complex task only when its officials have high enough talent levels $\theta$ as compared to the difference between the tasks' benefits and difficulties, and a high enough discretionary budget $D$. Performing complicated tasks requires talent, combined with sufficient resources to motivate those officials skillful enough to perform them. In determining whether there will be a nonzero probability of completing task $A$, talent levels and the budget act as substitutes. However, the extent of this substitutability is limited. Higher (lower) $D$ always means that lower (higher) talent levels are needed in order for the agency to perform task $A$. The opposite is not always the case. Some talent values can make the budget constraint irrelevant as a determinant of the type of task performed - however not the extent by which it is performed, i.e. the probability of completion. If $\theta^{\psi_{B}} d_{B}>\theta^{\psi_{A}} d_{A}$, for instance if the official's talent is close to zero, only task $B$ will be performed for any budget value. Similarly, if the official's talent level is close to one, only task $A$ is performed and there is no budget interval in which the agency shifts to the simpler task $B$. In this sense, talent availability is more important in determining the type of task the agency performs than the budget assigned.

\section{Welfare Implications of the Agency's Focus Changes}

The head's switches between incentivizing high-profile and basic cases do not generally serve society's interest. While the social welfare gains from handling cases and those from impression management spending will both be hard to quantify with much precision in practice, the latter even more so than the former, there is no reason to think they would generally be the same. In general, the net benefits to social welfare of impression management spending are ambiguous. Self-presentation towards building the organization's public image is a delicate exercise. On the one hand may public appearances create a wider public awareness of the agency, its interventions and the rules it enforces. A public image of a strong agency certainly is likely to help compliance with the rules it oversees. On the other hand, public signaling can just as well have negative effects. It could fuel suspicion of the agency being politically bound, poorly informed or myopically focused, for example, making the agency loose grip on its regulatees. A published sector study, criminal profile, or a code red warning, while possibly 
impressing the general public, can also give away crucial information about the agency's thinking to the initiated. Intended to come across authoritative and well-informed, such communications may reveal what the agency's blank spots are as well. ${ }^{25}$ In addition, zealously visible agency activity may lead to over-deterrence when perfectly fine activities are curbed for fear of being mistaken for a violation that would trigger an intervention and possibly sanctions.

In this section, we study how social welfare is influenced by the agency's focus changes resulting from changes in $D$. For simplicity, we analyze the case in which impression management on balance does not benefit society. The qualitative results carry through generally when relaxing this assumption, as discussed at the end of this section. Under the assumption that budget not spent on cases generates no welfare, expected social welfare net from spending $D$ is:

$$
E[W]=\Sigma_{i \in I} p_{i} d_{i}-D
$$

All tasks that the agency has not picked up have a probability of completion equal to zero. Note that this particular formulation of the social welfare function reflects the assumption made earlier that the entire budget is spent by the agency, i.e. no residue is returned to society. In addition, for analytical convenience we imply that the head's and the official's private utilities are negligible in total welfare, which amounts to assuming that as individuals they are atomistic in society.

In principle, given perfect information about the functional forms and the values of $\theta, \forall i:\left(d_{i}, \psi_{i}\right), \phi$, $V, \gamma$ - plus the gains from impression management when there are any - it is possible to determine the social welfare maximizing budget level in any given case. It seems unrealistic, however, to assume that the budget-setter would have all of this knowledge. It is therefore more interesting to study the welfare implications of a range of possible budgets - including those that would be socially optimal. Doing so reveals, amongst other things, that a change in the budget often affects welfare by more than just the resources allocated. ${ }^{26}$

While the agency head's utility is continuous in the assigned budget, social welfare is not. The head switches between rewarding one task and the other only at point(s) $D^{*}$, where his utility from the two reward schedules is equal. Welfare changes discretely then, with those task switches. Consider Figure 2, which continues the two task example set up above, for which social welfare reduces to:

$$
E[W]=p_{i} d_{i}-D
$$

where $i$ is the task rewarded by the agency head and pursued by the official. ${ }^{27}$ When the budget is non-binding, social welfare declines at a rate proportional to resources spent, since any additional

\footnotetext{
${ }^{25}$ See Schinkel (2011) on the interaction between market overseers and their overseen being a strategic game of catand-mouse, in which the question is who outsmarts who.

${ }^{26}$ We return to the problem of budget-setting under incomplete information in Section 6.

${ }^{27}$ In the example in this figure, parameter values are the same as in Figure 1.
} 
resources provided to the agency are extracted by its head.

Social welfare is linear in the probabilities of task completion, so that it is a linear function of the budget whenever the two probabilities are linear in the budget, as illustrated in Figure 1. Note that while the agency head always sets at least one of the rewards for the task completion higher than zero as long as there is a positive budget, society might be better off by not rewarding any of the tasks and simply keeping the discretionary budget instead. This is the case when the official's costs of effort are very high compared to the tasks' benefits and difficulty, so that the expected social benefits of the agency's discretionary activities do not justify the "investment" by society in additional rewards. Incentivizing an official with high $\gamma$ comes at a high price to society, yet not to the agency's head, who wants to offer nonzero rewards for task completion, irrespective of the official's costs, since lower effort caused by higher $\gamma$ translates into higher expected residual budget for the head to spend. In addition, the head prefers the opening of high-profile cases for show.

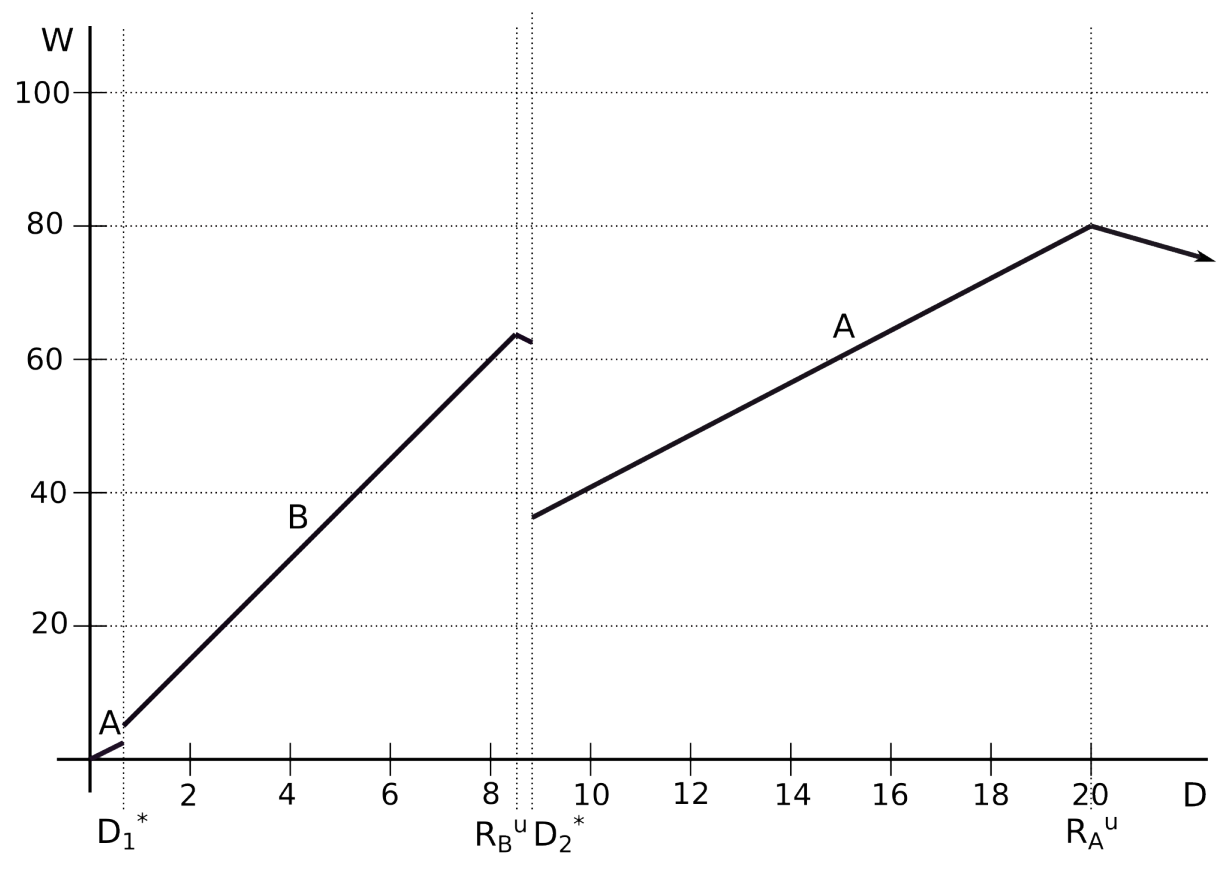

Figure 2: Social welfare as a function of the available discretionary budget.

In the wide range of circumstances under which society does want the agency's head to invest in additional effort by his staff, welfare develops as illustrated by a typical example in Figure 2. There are two local optima, at $D=R_{B}^{u}$ and $D=R_{A}^{u}$, respectively, with the second being the global welfare maximum. In particular, note that for budget levels just over $D_{2}^{*}$ marginal welfare is positive in $D$. While this may suggest that it is optimal to further increase the budget, in fact a discrete welfare 
increase can be had by slightly decreasing the budget over $D_{2}^{*}$. While moving away from the global maximum, this budget cut increases welfare through a decrease in the head's incentive to extract resources. Obviously, better is a large budget increase far towards, or best at, maximum welfare at $R_{A}^{u}$, but when that is not attainable, society may gain more from a budget cut than too small an increase. Finally, note that a discretionary budget squeezed below $D_{1}^{*}$ gives the head an incentive to just open high-profile cases.

Proposition 2 generalizes the results, establishing that the jumps in welfare always go in a predetermined direction.

Proposition 2. If a small budget cut occurs and the budget falls below any critical budget value $D^{*}$ such that the agency's focus shifts:

(i) from the complex task to a simpler one, social welfare discontinuously increases. ${ }^{28}$ The inverse is also true: a small budget increase bringing $D$ above such $D^{*}$ reduces welfare - even if $D$ is still below its welfare-maximizing level.

(ii) from a simple task to a more complex one, social welfare discontinuously decreases. ${ }^{29}$ The inverse is also true: a small budget increase bringing $D$ above such $D^{*}$ improves welfare.

Proof. See Appendix.

The agency head will design contracts leading to higher (lower) probability of completion of the complex (simple) tasks than would be society's preference, since these tasks have lower (higher) probability of being successfully completed upon an official's attempt, and the head receives higher fixed rewards from them. The wedge between the head's preferred and the socially optimal contract is due to the head's taste for impression management. Social welfare is discontinuous precisely at the points where the agency head switches between the contract designs. In Figure 2, there is a jump in welfare at points $D_{1}^{*}$ and $D_{2}^{*}$, since the agency head decides to stop rewarding the complex task when the budget drops below the critical value $D_{2}^{*}$, yet reopens the task once $D$ drops below $D_{1}^{*}$. Importantly, the jumps in social welfare caused by the change in the head's strategy can be of a very substantial size - around half of total welfare in our example. The size of the jump at point $D_{1}^{*}$ in Figure 2 is given by $\Delta W_{A, B}=D^{*} \times \frac{\theta^{2 \psi_{A}} d_{A}-\theta^{2 \psi_{B}} d_{B}}{\gamma}$, every time there is a shift between tasks $A$ and $B$ for budget values below $R_{B}^{u} \cdot{ }^{30}$

If we assume that the part of the budget that is spent on non-case specific activities does generate welfare, our general findings carry through, with some adjustments. First, if society values the impression management activities connected to opening big cases, the overall welfare increases. The head's incentive to open high-profile cases, $\phi d_{i}$ in the head's utility function, may be mirrored by $\phi^{S} d_{i}$ in the social welfare function $-\phi^{S}$ then captures the instantaneous social welfare gain of opening a case. The

\footnotetext{
${ }^{28}$ This case corresponds to $D_{2}^{*}$ in Proposition 1.

${ }^{29}$ This case corresponds to $D_{1}^{*}$ in Proposition 1.

${ }^{30}$ See the proof to Proposition 2 for the derivation and for the size of jumps occurring above $R_{B}^{u}$.
} 
agency's behavior remains unaffected by any change in the social welfare function and the generated welfare increases by a constant $\phi^{S} d_{i}$, dependent on the cases being performed under the given budget. In addition, for the parts of the budget where complex cases are being performed, this constant has a higher value. The social welfare function in Figure 2 shifts up by $\phi^{S} d_{i}$, more for the intervals where task $A$ is being performed (since $\phi^{S} d_{A}>\phi^{S} d_{B}$ ). Immediately then the size of the discontinuous jumps decreases. As long as society values the impression management utility from opening tasks less than the agency's head $\left(\phi^{S}<\phi\right)$, the existence and sign of the jumps remains unchanged. ${ }^{31}$

Second, the discontinuity of welfare in $D$ remains also when impression management financed by the discretionary budget spent on non case-specific activities is valued by society at $V^{S}$. Social welfare would then have the form $E[W]=p_{i} d_{i}-V^{S} p_{i} R_{i}+V^{S} D-D+\phi^{S} d_{i}$, similar to the head's utility function. This has an effect on the shape of the social welfare function which seizes being linear and becomes concave. As a borderline case, if welfare generation effects of impression management activities mirror the head's valuation (either because the agency head is fully benevolent, or as a mere coincidence), i.e. if $\phi=\phi^{S}$ and $V=V^{S}$, the social welfare function becomes continuous since it is exactly the same as the head's utility function up to a constant $-D$. Except from this extreme case, there is always a wedge between the head's utility and the social welfare, amounting to jumps in the social welfare function. Again, the sign of the jumps remains unchanged for the most relevant (and defendable case) $\phi^{S}<\phi$ and $V^{S}<V$, where the agency's head gains utility from the impression management in addition to the social welfare generated by it. ${ }^{32}$ Society's valuation of the residual budget has, however, an effect on the size of the jumps in the welfare function - they become smaller since $V^{S} \neq 0$ effectively makes the welfare function more like the head's utility. The differences between $(V, \phi)$ and $\left(V^{S}, \phi^{S}\right)$ determine the size of the jump.

Similarly, the discontinuity of welfare in $D$ remains also when any budget residue would be returned to society - somehow: as discussed in the introduction, bureaucracies tend to exhaust their resources and spend budget surplus to avoid future budget cuts. Social welfare would then be $E[W]=p_{i} d_{i}-$ $p_{i} R_{i}+\phi^{S} d_{i}$ since $V^{S}=1$, while the objective of the head is $E\left[U^{H}\right]=p_{i} d_{i}-V p_{i} R_{i}+V B+\phi d_{i}$, thus still leaving a wedge between the head's and society's dis-utility of paying the official. This difference remains for the arguably more likely head's objective function $E\left[U^{H}\right]=p_{i} d_{i}+\phi d_{i}$, which reflects that the budget residue is not at the head's discretion and therefore $V=0$.

Finally, consider the implications of different views on what government agencies produce for society. The determined direction of the welfare jumps of the type $D_{2}^{*}$ and $D_{1}^{*}$ described by Proposition 2 rests on the assumption that the head and society value the benefits generated by the tasks in the agency's portfolio in the same way, i.e. that the values of $d_{A}$ and $d_{B}$ are common. The social good that comes from the control tasks of the government agencies modeled, however, is not always obvious

\footnotetext{
${ }^{31}$ In the unlikely opposite scenario $\phi^{S}>\phi$, the sign of the jump depends also on the head's (and society's) valuation of the discretionary budget spent on non case-specific activities.

${ }^{32}$ For $\phi^{S}>\phi$ and $V^{S}>V$, the jumps go in the opposite direction. The remaining cases are ambiguous and depend on other parameter values.
} 
to the public. If society would instead perceive the benefits of the tasks differently, say as $d_{i}^{p}$ different from the actual welfare benefit $d_{i}$, the jumps in the social welfare can in principle have any sign and size. In particular does it seem reasonable to consider the case in which the agency's behavior is driven by society's perceived tasks' benefits $d_{i}^{p}$, since the head will be evaluated by budget-setter with that perception. While a mission-motivated agency's head might then still use the true $d_{i}$ as a measure for determining the agency's performance, a head who is more interested in the public perception - which would ultimately affect future budgets, of his agency's activity would instead aim at $d_{i}^{p}$.

To see some of the possible welfare consequences of an asymmetric understanding of society's benefits, consider a head who is interested in an appearance of performance $\left(p_{i} d_{i}^{p}\right)$, and a public that considers more difficult tasks to be of higher significance than they actually are - for example because of their greater exposure in the media - i.e. $d_{A}^{p}>d_{A} \cdot{ }^{33}$ Such a public misconception has a negative impact on welfare. From a social welfare point of view, the head already stimulates too much take-up of the more difficult task $A$. A public over-assessment $d_{A}^{p}>d_{A}$ further increases the rewarding of task $A$ at the expense of task $B$, with negative consequences for social welfare.

Similarly, $d_{B}^{p}>d_{B}$ (or equivalently $d_{A}^{p}<d_{A}$ ) can cause the jumps in perceived and actual social welfare to have opposite signs. Consider the case $d_{A}^{p}=d_{A}$, while $d_{B}^{p}>d_{B}$. If the public overestimates the impact of the simpler tasks and the agency head adjusts his choice accordingly, the jumps in the perceived social welfare smoothen, while the jumps in the actual welfare remain governed by the same formula as before - only do they happen at different budget levels. If the perceived welfare gains from the simpler tasks become much higher than what they actually are, the jumps in the perceived welfare function would have an opposite sign. ${ }^{34}$ Clearly, the existence of asymmetries between actual welfare effects of cases and their public perception can have deeply detrimental effects with agency heads concerned with impression management.

\section{Agency with Several Officials and Multiple Tasks}

The main insights derived from the basic model above extend straightforwardly to an agency employing a number of officials and having several types of tasks that it can perform in addition to its regular duties, under the following three assumptions. First, we assume that contracts can be individualized and the head can fully discriminate among his officials. This is in line with the examples of secondary and tertiary personal rewards given above, as well as with the assumption that the agency head has perfect information about his staff's qualities. Second, if two officials perform one and the same type of task, their probabilities of task completion are independent, i.e. there is no interaction or economies of scale or scope - which can be thought of as each official individually working on a different task of

\footnotetext{
${ }^{33}$ Assume $d_{B}^{p}=d_{B}$.

${ }^{34}$ See the proof to Proposition 2 for a derivation of the values for $d_{i}^{p}$ for which the jump in the perceived welfare function disappears. $d_{i}^{p}$ being above or below these values then directly determines the direction of the jump.
} 
the same type. Third, interpreting the discretionary budget as an administrative constraint on the head's rewarding options, we assume that it is an upper limit on the reward for each official - that is, in case the agency employs $m$ officials, the head uses up to $1 / m$ of the total discretionary resources to motivate each official. At the end of this section, we briefly discuss why alternative specifications, while introducing considerable complexity of analysis, do not change our results qualitatively.

In this setup, the mechanics of the head's switching between the available tasks remains unchanged, including the formulas for critical values of budget. ${ }^{35}$ The head's most preferred task for each official without a binding budget is given by Lemma 2. The main difference when more tasks are available to the agency is that there can be more critical values of the budget at which the head switches the agency's focus, as these can happen among multiple pairs of tasks for different budget values. One of these tasks will still be more difficult and yield higher benefits upon completion. ${ }^{36}$ The head always has one preferred task for the official to perform for a given budget value, and the changes in priorities are always between two tasks, just as described in Proposition 2. Moreover, the intuition of Proposition 1(ii) directly implies that for the lowest budget values the head will always incentivize the most complex tasks, as they have the highest fixed reward for opening. Only if $\phi=0$ will the agency perform continuously simpler tasks as the discretionary budget depletes towards $D=0$. For an agency with $k$ officials and $n$ tasks to choose from, there are between 0 and $k \times n$ jumps in performance, as the head's level of discretion decreases. ${ }^{37}$

Figure 3 depicts a simple parametrization, in which the agency entails two officials and there are three types of tasks that each of them can perform. ${ }^{38}$ The two officials $O_{1}$ and $O_{2}$ differ in their talent level, $\theta_{O_{1}}<\theta_{O_{2}}$, while the tasks are ordered by difficulty as $\left(d_{A}, \psi_{A}\right)>\left(d_{B}, \psi_{B}\right)>\left(d_{C}, \psi_{C}\right)$ for official $O_{1}$ and $\left(d_{X}, \psi_{X}\right)>\left(d_{Y}, \psi_{Y}\right)>\left(d_{Z}, \psi_{Z}\right)$ for official $O_{2}$. For each budget interval, staff might get "assigned" to a different task via the contract design. The contracts offered to each of the two officials and the resulting tasks picked up are still governed by Lemma 2 and Proposition $1 .^{39}$ In our

${ }^{39}$ Lemma 2 determines the task that will be picked up by the official when the budget constraint is not binding. Take the official $O_{1}$ and the most complex task he can perform, $A$. The critical budget values derived in the proof to Proposition 1 then determine whether a simpler task will be performed for some budget constraints - we know that task $A$ will be performed for the lowest budget values as well. However, there are now up to six possible critical budget values instead of just two: a jump from task $A$ to task $B$, from $A$ to $C$, from $B$ to $C$, and each of them back. Their ordering determines which task will be performed for a particular budget value. There can be an interval in which task $B$ is preferred over task $A$, an interval in which task $C$ is preferred over task $B$, and an interval in which task $C$ is preferred over task $B$. For instance, the official $O_{1}$ could perform task $A$ for the highest and lowest budget values and task $C$ for some intermediate values without ever performing task $B$. This would happen if the interval in which $B$ is preferred
} 
example, both officials are offered contracts that induce them to perform the most complex task from their portfolio when the discretionary budget constraint is non-binding, and are gradually pushed to tasks with a lower level of complexity when the discretionary reward that a the head can offer goes down. ${ }^{40}$ For the lowest ranges of $D_{i}$, it becomes worthwhile for the head to make every official pick the most complex task, even those that are not cut out for them, because of the head's incentive to open cases for exposure. For low enough budgets, impression management, rather than productivity of the official, becomes the most important determinant of what is being rewarded by the agency's head.

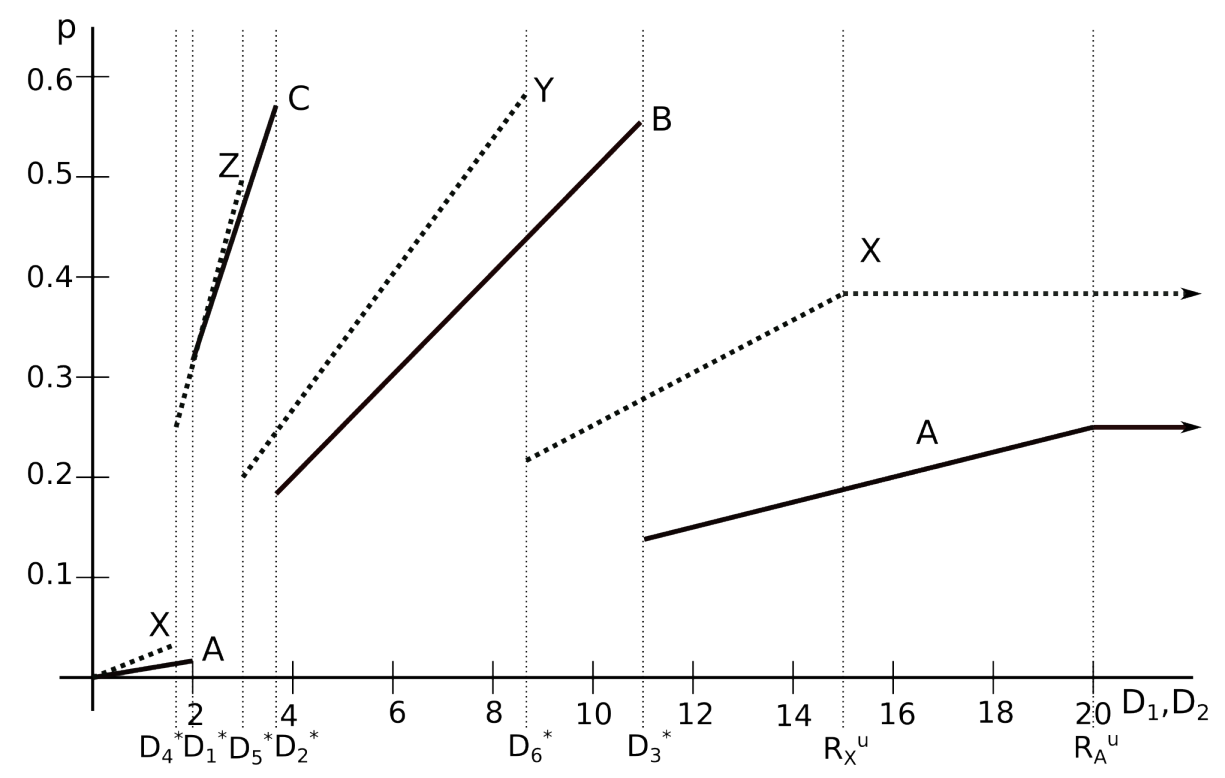

Figure 3: Probabilities of task completion in an agency with two officials, $O_{1}$ (solid lines) and $O_{2}$ (dashed lines), each with three tasks to choose from.

Figure 4 displays the welfare function to the above illustration of agency's performance, assuming again that impression management is socially unproductive on the whole. ${ }^{41}$ On every continuous part of the social welfare function, each official picks one task as is indicated in the figure. The jumps in welfare follow a pattern similar to that in the two-task case. There is an increase in welfare when the budget falls below a critical value for other than the lowest values, caused by a decrease in the expected resources spent on impression management. However, for lower discretionary budget values, the incentive to open big cases for presentation purposes causes a prioritization towards complex tasks

over $A$ is a subset of the interval in which $C$ is preferred over $B$.

40 This is a result of the parametrization that we have chosen for our numerical example. It is plausible to construct examples where officials are induced to perform only one type of task or just a few of them. For instance substantially increasing the talent level of official $O_{1}$ would make him skilled enough so that the agency's head would make him perform task $A$ no matter the budget constraint.

${ }^{41}$ In the example in the figure, parameter values are the same as in Figure 4. 
to the detriment of social welfare.

For budgets above $R_{A}^{u}$, prioritizing the complex task $A$ generates negative welfare, since incentivizing it serves the head's personal preferences for impression management, but this type of task is too complex for society's good. ${ }^{42}$ The much higher benefits that would materialize upon its completion cannot offset the low probability of success for this hard task. Similarly, the social benefits from task $X$ are decreasing in resources above $R_{X}^{u}$, where the reward for official $O_{2}$ reaches it's cap, below zero for large enough budgets. Social welfare can also be negative for low or intermediate budget values. In such cases, society would be better off dismantling the agency altogether, rather than getting the discretionary budget constraint wrong.

The absolute size of the welfare jump discontinuities is governed by the same formula as in the case of one official choosing between two tasks only, yet each jump is smaller relative to overall welfare, because generically each is caused by a single official switching between tasks, while the others remain on theirs. The fact that in the case of a still relatively simple agency the number of local maxima of the welfare function generated by the discretionary spending is already large underscores the importance of considering task prioritization when devising the budgeting policy by any agency's superiors. For agencies with more officials and tasks, the jumps become less pronounced, but the overall welfare function is in general not monotonous.

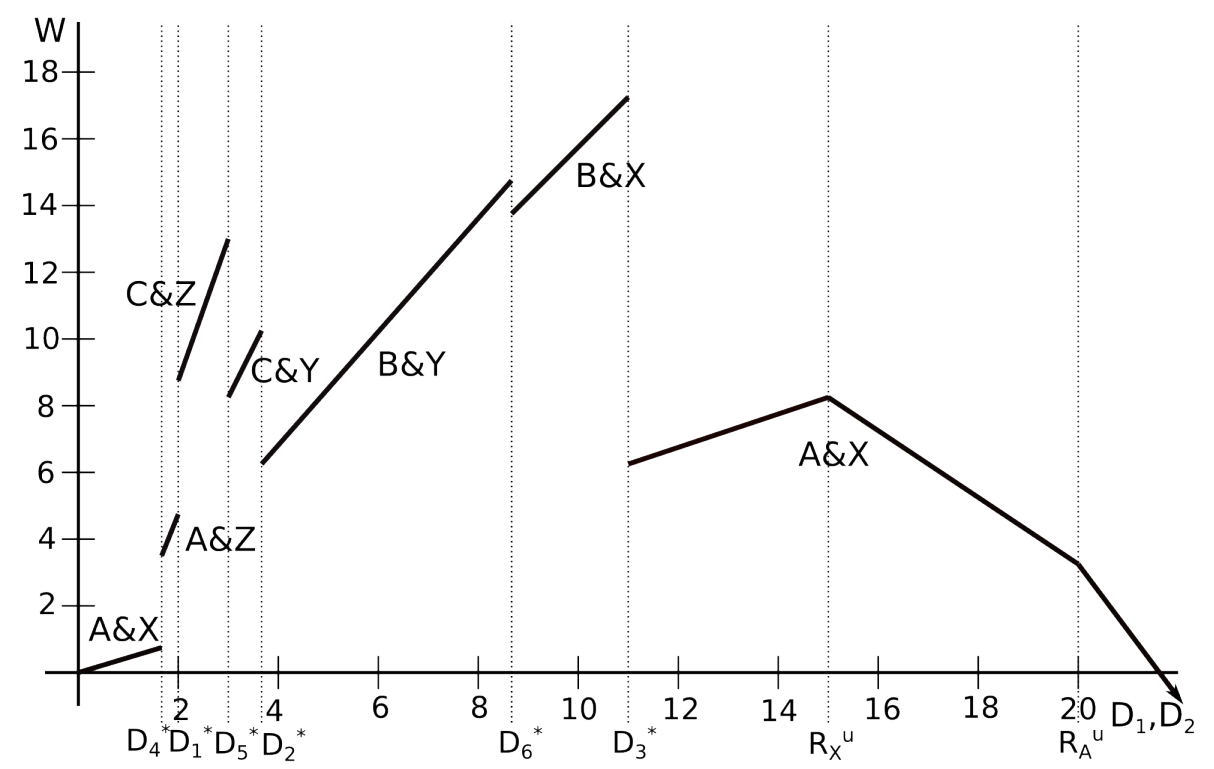

Figure 4: Possible welfare effects of discretionary spending in case of two officials with three tasks to prioritize.

\footnotetext{
${ }^{42}$ The difficulty of task $A$ is set to generate zero social welfare up to $R_{A}^{u}$ when performed by a official with talent level $\theta_{O_{1}}$, so that all welfare on intervals where task $A$ is performed comes from the activity of the official $O_{2}$.
} 
As the number of officials rises, the welfare effect of individual jumps becomes less pronounced, but there is likely to be more of them. More tasks affects the agency's behavior depending on their characteristics relative to the existing portfolio. Adding a simplest task or a task of intermediate difficulty may have no effect at all. Adding a new task that is more complex and beneficial than any existing one always has an effect on both the tasks being picked up and welfare, since it will be performed by all officials for the lowest budget values, and may be performed by the most talented officials for other budget values. If tasks of intermediate difficulty and yield are added, the size of the welfare jumps might decrease, for example because some jumps among tasks with very differing characteristics can be replaced by two smaller-sized jumps among similar tasks.

A full continuum of available tasks with differing characteristics effectively flattens out the welfare function, in the sense that at every point of the budget constraint there is a infinitesimal small jump and each task is performed only for a specific budget value. ${ }^{43}$ Note that still in that case task switching determines welfare, in the sense that neglecting the head's changes of mind will underestimate the effects from discretionary budget changes - discretely so for any finite number of tasks as soon as the budget is moved over a jump discontinuity threshold. Since each discontinuity is effectively the result of one (or more) officials being incentivized to perform a different task, the jumps will be affected by introducing society's nonzero valuation of the impression management in the same manner as in Section 4. The sign of the jumps remains unchanged, as long as the agency's head gains some utility from the impression management in addition to its welfare generating effects. The size of the jumps then again depends on the wedge between society's and the head's valuation of these activities.

Finally, consider variations of the three simplifying assumptions made at the beginning of this section. Should, for legal reasons for example, the agency have to offer all, or classes of its officials the same incentive contracts, so that the head cannot exercise full discretion in awarding his staff, he could still write one or several universal contracts that include cut-off values in the reward structure. Effectively, officials with talent in certain intervals would choose to perform certain tasks. Because of the incentive constraints, the agency's head might then have to leave information rents to some officials in order to induce them to perform certain tasks. Yet the main results carry through. The same is true for allowing officials to jointly work on a case and so affect its probability of successful completion. This would highly complicate the analysis, yet still return abrupt shifts in performance caused by changing the budget to the head's discretion. Finally, the budget constraint could be modeled alternatively as the maximum total money spent if every official who is offered a reward is successful in completing its task. If such reallocation of resources among officials becomes part of the head's decision space, the model dynamics would change substantially, since a change in the budget can then amount to changes in any number of contracts between the head and the officials, and the agency head would get to decide for which officials or tasks the budget is effectively (non)binding. Again, while considerably

\footnotetext{
${ }^{43}$ Do note that it cannot simply be the case that doubles $\left(d_{i}, \psi_{i}\right)$ cover the whole $R_{+}^{2}$, since then the task with $\psi=0$ and $d=\infty$ would dominate all others and always be chosen by the head. A continuum of tasks could instead look for instance like $\left\{\left[d_{i}, \psi_{i}\right] ; \psi_{i}=\frac{1}{2} d_{i} \& d_{i} \in(1,100)\right\}$.
} 
more complex to assess where and by what extent, is would result in jumps in the agency's priorities and welfare all the same.

\section{Optimal Discretionary Authority}

Society employs the agency head for his expertise. Yet while the head's private information about his staff's best talent-task matches gives him the ability to maximize his agency's contribution to social welfare, his personal tastes for self-presentation through non-case-specific activities with less obvious social benefits means he has to be kept in check. Apart from appointing a head whose incentives are closest to the public interest, society has the budget part over which it gives the head discretion, $D$, to do so. The political decision on a government agency's budget is two-fold: it concerns the agency's total budget, as well as its division between the non-discretionary part and the discretionary part $D$. To the extent that this division is determined outside the agency, it defines the discretionary space of the agency's head. While an authority's budget-setter is unlikely to have the information required to determine $D$ socially optimally, there are several qualitative insights to go by.

The socially optimal split of the total budget depends crucially on the welfare that is generated by generic tasks, relative to what can be obtained in addition through discretionary spending. Let $F$ be the part of the generic budget in which welfare is smooth, including expenses for work facilities and support staff, as well as fixed wages for regular agency's activities that are readily assigned by law and require no special expertise beyond the common agency standard of professionalism or prioritizing, such as common random inspections to monitor compliance. For any agency that is socially productive, it seems reasonable to assume that the welfare function in generic resources spent on regular agency activities is concave, without discontinuities and with a maximum above which the marginal benefit of funding the agency's generic tasks is lower than its marginal costs. Suppose that $F$ has diminishing returns to society, that is, let net welfare as a function of $F$ be $W_{F}(F)$, strictly concave with a maximum at point $F=\hat{F}$.

The optimal division between $D$ and $F$, given a fixed total budget, then depends on the shape of the welfare function generated by the discretionary spending, relative to the shape of the welfare function generated by the performance of the generic task. A budget-setter with perfect information about the shape of both of the (expected) welfare functions $W_{D}(D)$ and $W_{F}(F)$ would in principle want to divide any budget total so that the marginal welfares generated by the two budget chapters are equalized. There are two caveats to this. First, such a split might not exist due to the discontinuities in the welfare function of the discretionary spending. In that case, the division should be made so that the discretionary funds are kept on the "correct side" of the jumps as discussed in Section 4, and the rest of the funds is assigned to the performance of the generic tasks. Second, equating the marginal welfare gains is not sufficient for attaining the optimal division, since $W_{D}$ is non-monotonous and typically has several local maxima. A welfare-maximizing division of a given total budget thus 
has to be determined on a case-by-case basis, requiring immense information about the agency's inner workings, it's various tasks and the characteristics of those people performing them - exactly the type of information only a head would have and a government would hire him for.

Figure 5 provides a graphical illustration of the problem faced by the budget-setter for the baseline case in which the non-case specific spending is unproductive. Suppose first that he has perfect information. The optimal total budget and the optimal budget split are simply found using the global maxima of both $W_{D}$ and $W_{F}$. The socially optimal total budget is $\hat{F}+\hat{D}$ and the socially optimal budget division is $F=\hat{F}$ and $D=\hat{D}$. If that optimal total budget is not available, the optimal split in Figure 5 can be determined as follows.

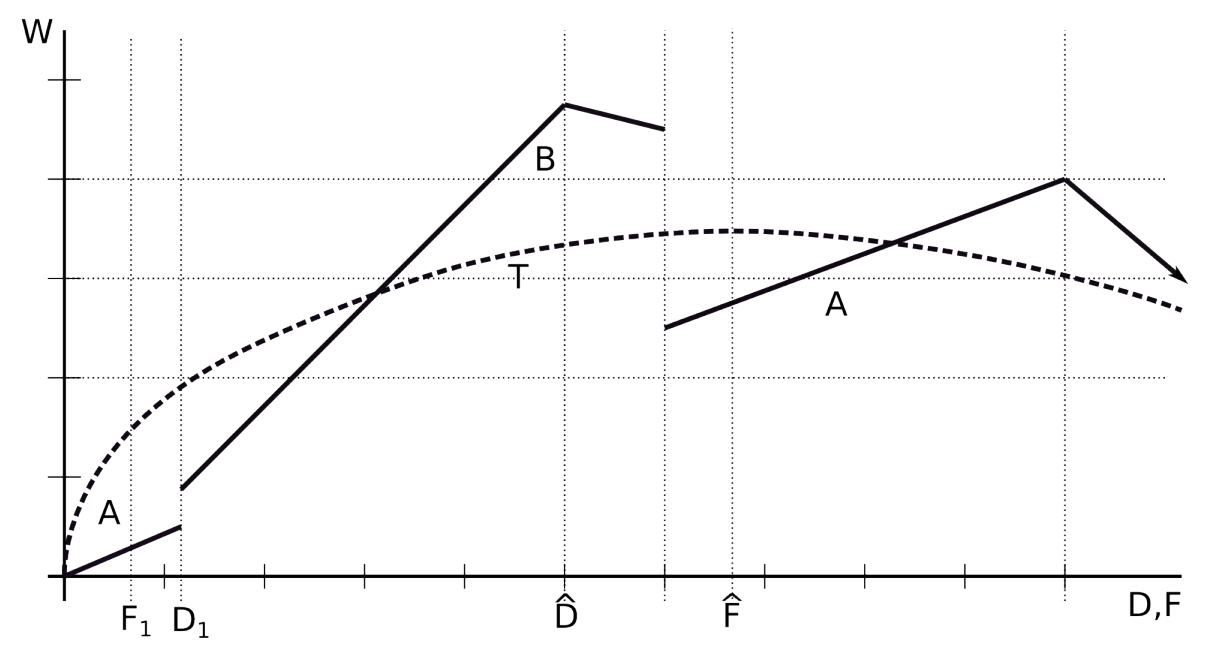

Figure 5: Welfare generated by generic (dashed line T) and discretionary (solid lines A, B) budget spending.

For very low values of the total budget $F+D$, all funds should be channeled to the generic task performance because of its higher marginal welfare, i.e. $W_{F}^{\prime}(0)>W_{D}^{\prime}(0)$. There is no point in allocating any resources to the discretionary task performance lower than $D_{1}$, but that does not mean that it will be financed as soon as $F+D \geq D_{1}$. Specifically, if there are just enough funds to induce the agency's head to promote the performance of task $B$ (i.e. $F+D$ is just enough to attain the first jump in the discretionary performance), all funds should still be used to finance the generic task since it generates higher welfare. In fact, all funds should be allocated to the generic task's budget $F$ as long as $(F+D) \in\left(0, F_{1}+D_{1}\right) . F_{1}$ in Figure 5 is defined as the value of $F$ for which $W_{F}^{\prime}(F)=W_{D}^{\prime}\left(D ; D \in\left(D_{1}, \hat{D}\right)\right)$, i.e. the marginal welfare gain of additional investment in $F$ equals the slope of the discretionary tasks' welfare function on it's interval $\left(D_{1}, \hat{D}\right)$ - the linear part after the first jump. With the budget total reaching $F+D=F_{1}+D_{1}$, a perfectly informed budget-setter abruptly cuts $D_{1}$ from the resources allocated to the performance of the generic task $T$ and start financing also 
the discretionary tasks' performance. For any total budget in the interval $(F+D) \in\left(F_{1}+D_{1}, F_{1}+\hat{D}\right)$, the optimal budget division is $F=F_{1}$ and $D$ the remainder. The discretionary budget is thus financed until $W_{D}(D)$ reaches it's maximum, with the generic task financing being constant at $F=F_{1}$. Finally, for total budget $(F+D) \in\left(F_{1}+\hat{D}, \hat{F}+\hat{D}\right)$, the optimal split is $D=\hat{D}$ and $F$ the remainder. Note that this is but one example of solving the budget-setter's problem with given total resources and using the welfare functions given in Figure 5, but other scenario's are analogous.

Now consider a budget-setter with imperfect information. While the first-best budget division will generally be out of reach in this case, some information about the officials' costs or an estimate of the head's preference for impression management, together with the knowledge of $W_{F}$, can go a long way in setting a reasonably good level of discretion. A strong preference for impression management implies that the maximum incentive contract rewards will be relatively low, speaking for narrowing the discretionary space. At the same time there may be a negative impact of tightening the head's discretionary budget too much, since it can edge him towards having high-profile cases being pursued unsuccessfully for the exposure they generate. Overall, the jump discontinuities in $W_{D}$ remain the prime determinants of the optimal division of the budget, but the budget-setter is unlikely to have full knowledge of $W_{D}$.

If the agency's superiors have limited information about the shapes of $W_{F}$ and $W_{D}$, the question who should determine the budget total and the budget's division gains relevance, and it comes down to the characteristics of the agency's head. A fully benevolent agency head would himself promote the optimal budget division and assign appropriate funds to generic tasks as their performance also enters his utility function. A partially benevolent agency's head with preference for discretionary spending might still allocate part of the resources to the generic tasks' performance, depending on his relative utility gain from the agency's welfare generation and advancement of his private goals via less productive discretionary spending. Whether or not the agency's head should then be allowed to determine the budget division depends both on the quality of the budget-setter's information about the head's motivations and about the shapes of $W_{F}$ and $W_{D}$. Both how much discretionary space a given agency head should have, and whether he should be able to partially determine the extent of it himself, all depends on the level of alignment between the head's motivations and society's interests. Moreover, in determining the discretionary space of the agency head, the budget-setter can limit the extraction of resources, but thereby also reduces the benefits from the head's superior information on how to incentivize the officials. If impression management activities would also generate welfare, the heuristics of finding the optimal total budget and optimal budget division do not change, even though the shape of $W_{D}$ is altered. The more social benefits come from impression management, the more discretionary space and influence over the budget split the agency's head should be given. 


\section{Concluding Remarks}

This paper offers a formal model to study task prioritization under a binding budget constraint in government agencies with multiple tasks to be picked up by staff with varying talent that is managed by a head who balances several interests. We find that the size of the agency's discretionary budget influences not only the scale, but also the type of tasks it will engage in. Social welfare is non-monotonic and discontinuous in the agency's budget. Small changes in the budget over certain thresholds may cause extensive restructuring from major to minor tasks, or vice versa. For lower binding budgets, the head continues to sub-optimally incentivize work on complex tasks, when the agency should have shifted down to simpler tasks. Looking locally at marginal welfare can give a budget-setter the wrong idea about socially optimal budget changes. Budget cuts can increase welfare more than too little extra budget would, whereas a substantially higher budget would be socially optimal. By determining the size of the discretionary space of the agency head, the budget-setting body can indirectly control the type of tasks being pursued.

Our findings underline the importance of socially optimal institutional design and budgeting for government agencies. Policymakers should consider not only the effects of budget changes on the scale of the agency's activities, but also the type. In that, the size of the discretionary budget is a control tool with important welfare implications. Discussion about which tasks and tools to make available to a government agency should not be separate from determining the resources it will have at its disposal. They are complementary, both directly and indirectly. Moreover, the optimal sets of tasks and tools for an agency are subject to such realities as availability of skilled staff, means of secondary and tertiary performance rewards, and the interests of the agency's head.

Any agency superior, in first instance usually a Ministry, should be aware of its crucial role in tasking its agencies. To a government that has to save a certain amount across different agencies, our model suggests that these cuts be allocated where there is a bigger chance for a higher welfare jump upwards - i.e. where agencies have taken on high-profile cases too ambitious for their limited means. In practice, however, it will be difficult to tell how close to a welfare jump any given agency is, and so what would be optimal cuts and reassignments. In addition, in many agency practices the truly discretionary budget is stochastic, as high-priority cases - be it a terrorism threat, a tax scandal, or a merger notification - present themselves unannounced and then must be dealt with.

One possible instrument to better control priorities is to compartmentalize the discretionary budget, earmarking parts for designated classes of cases. To do so to improve welfare, however, requires a considerable amount of information that budget-setters typically would not have. While requirements on an agency to return left-over budget appear appealing to impose, they may not be effective either. Even if government were able to tell what amount of the budget was not spent on which cases, the return requirement would lead to rewards going up, as the head would no longer care about a residue and rather spend the entire budget. This might lead to a different type of wasteful spending, even 
though the incentives of the agency's head are now more aligned with society's interests. Moreover, the head's instantaneous incentive to open up high-profile cases for impression management purposes remains.

Another possible institutional design element that could help counter the head's urge to extract budget is to feed back part of the revenues from fines imposed by the agency directly into its budget. Doing so introduces another set of potentially perverse incentive problems, pushing for priorities for picking low hanging fruits with little social harm, if not fostering a steady crop of violations to harvest later on. Yet, it would in principle counter the head's inclination to spend resources on cases that are a likely loss for their short-run impression management features. The more indirect feedback from agency success into budget increases may be a better instrument for curbing excessive impression management.

At the same time do our findings reveal how both institutional design and budget can be used to pursue political goals or promote private interests. By either steeply reducing the budget or, instead, over-financing the agency, its focus of attention can be shifted from low-risk welfare increasing tasks to high-profile cases that will ultimately fail. Similar effects follow from extending the spectrum of tasks the agency is made responsible for, without also offering a matching budget. Parliaments better control their governments not to abuse these mechanisms, when they value the independence of their government agencies.

To return to our lead example of competition authorities, one structural form of reorganization of agencies is institutional mergers. In the U.S., the debate on merging the DoJ's Antitrust Division with the FTC into one competition authority has been long, yet rather academic. In Europe, meanwhile, several Member State authorities, including those in the United Kingdom, The Netherlands and Spain, have recently gone through extensive institutional reorganizations, that also included mergers with other agencies such as sector regulators and consumer authorities. An emerging literature studies the effectiveness of such institutional changes for market oversight by looking at the costs of the merger itself versus merger specific efficiencies in eliminating dual enforcement and expected gains from complementarities, the importance of a unified mission, and effects from regulatory competition lost. ${ }^{44}$ Our formalized approach adds the importance of the interaction between the combined talent pools and resources of the previously separate agencies, together with the new head's objectives, in determining the emphases that the merged agency will lay in the execution of its enlarged set of tasks. While there may be synergies in enforcement, an institutional merger can result in the more expertise and resource demanding duties being largely abandoned, if the two original agencies differed sufficiently in their tasks and talent pools, so that the smaller new budget is channeled to incentivize mostly simple basis cases, at the expense of the complex major tasks. Such a shift in the agency's performance is accompanied by a sudden unanticipated increase in social welfare. On the other hand, the head can possibly use the joined discretionary budgets across the merged agencies to increase a

\footnotetext{
${ }^{44}$ See Crane (2011) and Blumenthal (2013).
} 
reward for a particular set of tasks, while decreasing other rewards, to ambiguous welfare effects. Our model can advise on the types of tasks that would be best combined under one roof.

A number of extensions of our analysis present themselves. A public agency might be able to influence the skill level of its employees through recruitment, training and on the job skill growth. Staff quality is also endogenous in the sense that an agency that continuously does menial work will loose high quality staff and cannot hire better, whereas in a challenging institutional environment, the quality of work may spiral up, as the agency attracts talented officials. The quality of the agency's talent pool directly affects its responsiveness to incentives and hence budget changes. A fuller model would include endogenous dynamics, as well as choices on human resources management within the agency as part of the head's discretionary space. Increasing talent need not necessarily be beneficial: while within-case productivity may go up, in addition to the cost of training, the head may stimulate the more complex tasks more, leading to ambiguous welfare effects. Also, the head need not necessarily have the best intentions in this respect either: depending on his preferences and the agency's circumstances, the head may prefer a staff that is below the socially optimal standard - which he can cheaply induce to take on complex cases it will not be able to complete successfully.

One possible institutional safeguard against an agency head's preferences dictating his agency's priorities is to install an executive committee or board to lead the agency instead of a single head, which is often the case. While this would introduce extra complexities of joint decision making, there is a priori no reason to think that some members of such a committee would have strong motivations to counter a typical head's incentives - after all, they are all in the same position now. As long as sufficiently many committee members would value impression management activities for the agency, our basic results remain. In principle, the same is true for more complex multi-layered organizations, with division heads and a central agency head, although some of the personal gains from impression management are to be split among the committee members. While interesting questions about countervailing arguments in delegating arise, the type of findings we obtain seems rather robust. Likewise would a fuller description of the agent as a case-handling team of officials enrich our analysis.

The non-monotonicity of the welfare function in the budget is related to the limited set of cases of certain discrete sizes that the agency can choose from. A more continuous set of tasks for each official to perform can smoothen the welfare function. Yet a policymaker will still likely over- or underestimate the welfare impact of a budget change on the upper welfare envelope parts where shifts towards less complex tasks occur with a budget cut. Moreover, while the nature of the tasks performed by the type of government agencies considered in this paper is that they are discrete and of a certain, and typically large, minimum size, to that each task commits a chunk of resources to complete once opened, more cooperative types of enforcement, such as settlements, may also reduce the sizes of the jumps. Following public prosecutors plea bargaining in criminal cases, competition authorities increasingly seek to settle cartel cases, or obtain commitments. By effectively reducing the resources and time that need to be committed to a case, settlements make it possible to pursue more cases with the same overall 
budget and same number of staff. To accommodate such a scenario, our model could be extended to officials that can pick up more that one task and split their effort among them. This may reduce the sizes of the welfare jumps at agency focus shift points, in a similar way as adding more officials into the baseline setup does, but will not eliminate them. The discontinuities will become less pronounced, as each task's performance constitutes a lower share of the total expected welfare. Yet, some level case discretion will always remain, as settlements still require extensive case preparation.

Our results are obtained for a head who has perfect information about his officials' talents. A natural extension is to assume that the talent level is private information of the official and the agency head knows only the ex ante talent distribution. Under asymmetric information, our qualitative findings remain. It implies that the individualized contract offered to an official is driven by the head's expected utility of the official's choice of tasks multiplied by their respective probabilities of being performed. In a setting with one difficult and one basic task, the agency head uses the contract design to set a "cut-off value" of the draw from the official's talent distribution above which the official chooses to perform the difficult task, and below which he performs the basic task. The official thus ex ante performs each task with some probability. If the budget is binding, this comes at a cost: in order to satisfy the incentive constraint of an official with a high talent draw, the reward for the basic task has to be set below the head's desired level. The difference increases as the discretionary budget becomes tighter, because the official with high talent draw is rewarded less and less optimally from the head's point of view. Once this cost becomes higher than the head's utility of having the officials with higher talent draws perform the more difficult task, the agency's head stops rewarding the complex task altogether and increases the reward for the simple task, because he is no longer bound by the ex ante incentive constraint of the official. This will generate a jump in the probability of performing each task and a discontinuity in the social welfare function. Moreover, if the agency's head gains nonzero utility from opening a big case, there will be a shift towards performing complex tasks for the lowest budget values, just as in the model without information asymmetry. Introducing the information asymmetry thus changes the critical budget values, but the main message of the model holds: the head's switching between task types creates discontinuities in the social welfare function. Moreover, agency performance remains suboptimal when the head gains utility from socially less productive impression management.

Another ready extension is asymmetric information about the characteristics of the available tasks their complexity and the benefits they bring to society and the agency's head. We assume an "expert" agency head who has perfect information about the agency's possible undertakings. If he has not, a wedge is driven between formal and real authority in the agency, similar to that in Aghion \& Tirole (1997). While the head retains the formal authority - that is, the right to overrule the official's selection of the task to perform - the officials would have a real authority over the task pickup, whenever some level of authority delegation is optimal for the agency's head, for example when the costs of obtaining the relevant information is too high. In our basic setup, the official's private benefits of task completion were set at zero, for simplicity of analysis. If instead there is a difference between the private benefits 
of the tasks' completion of the head and those of the official, and the officials have private information about the tasks' characteristics, the effects of the agency's prioritization with a shift in the discretionary budget assignment are ambiguous. The head is bound by the incentive constraint of the official, unless he can discover the relevant information himself - at a cost. Should these costs be too high for some types of tasks, the head may stop rewarding them as feasible missions completely. This would effectively decrease the number of tasks in the official's choice set, and amount to more abrupt shifts in the agency's performance and the resulting welfare. Alternatively, the agency's head may need to leave the better informed official a rent in order to satisfy his incentive constraint, possibly resulting in a less efficient allocation of resources.

Finally, our model can be extended to the political economy of budget assignment, focusing on the relationship between the head and his (direct and indirect) superiors, politicians, who have their own incentives. We noted that politicians may abuse the agency budget to steer its task take-up. One possible reason for a politician to may want to do so is to please his constituency. A lobby from industry with the responsible Ministry against the competition authority's perceived aggression on discovering and sanctioning cartels may result in either budget cuts or enlargements - depending on where the agency is on the case type spectrum. Another mechanism is to modify the head's incentives by changing the criteria by which he will be assessed. On the other hand, the head has tools to influence public opinion, which also interests politicians. Through impression management, the head

can produce public support, which may translates into pressure on politicians to enlarge the agency's budget.

\section{References}

Aghion, Philippe, \& Tirole, Jean. 1997. Formal and Real Authority in Organizations. Journal of Political Economy, 105(1), 1-29.

Alesina, Alberto, \& Tabellini, Guido. 2007. Bureaucrats or Politicians? Part I: A Single Policy Task. American Economic Review, 97(1), 169-179.

Alesina, Alberto, \& Tabellini, Guido. 2008. Bureaucrats or politicians? Part II: Multiple policy tasks. Journal of Public Economics, 92(3-4), 426-447.

Baker, Jonathan B. 2003. The Case for Antitrust Enforcement. Journal of Economic Perspectives, 17(4), 27-50.

Barzelay, Michael. 2001. The New Public Management: Improving Research and Policy Dialogue. University of California Press.

Benabou, Roland, \& Tirole, Jean. 2003. Intrinsic and Extrinsic Motivation. Review of Economic Studies, 70(3), 489-520. 
Blumenthal, William. 2013. Models for Merging the US Antitrust Agencies. Journal of Antitrust Enforcement, 1(1), 24-51.

Crane, Daniel A. 2011. The Institutional Structure of Antitrust Enforcement. Oxford University Press.

Dewatripont, Mathias, Jewitt, Ian, \& Tirole, Jean. 1999. The Economics of Career Concerns, Part II: Application to Missions and Accountability of Government Agencies. Review of Economic Studies, 66(1), 199-217.

Fisher, Franklin M., McGowan, John J., \& Greenwood, Joen E. 1985. Folded, Spindled and Mutilated: Economic Analysis and U.S. vs. IBM. The MIT Press.

Francois, Patrick. 2000. 'Public Service Motivation' as an Argument for Government Provision. Journal of Public Economics, 78(3), 275-299.

Francois, Patrick. 2003. Not-For-Profit Provision Of Public Services. Economic Journal, 113(486), C53-C61.

Gal, Michal S. 2004. The Ecology of Antitrust: Preconditions for Competition Law Enforcement in Developing Countries. Competition, Competitiveness and Development (UNCTAD), 20-38.

Hyman, David A, \& Kovacic, William E. 2013 (Feb.). Competition Agencies with Complex Policy Portfolios: Divide or Conquer? SSRN Scholarly Paper ID 2110351. Social Science Research Network, Rochester, NY.

Kovacic, William E., \& Hyman, David A. 2012. Competition Agency Design: What's on the Menu? European Competition Journal, 8(3), 527-538.

Kovacic, William E., Hollman, Hugh M., \& Grant, Patricia. 2011. How Does Your Competition Agency Measure Up? European Competition Journal, 7(1), 25-45.

Kreps, David M. 1997. Intrinsic Motivation and Extrinsic Incentives. American Economic Review, 87(2), 359-364.

Laffont, Jean-Jacques, \& Martimort, David. 1999. Separation of Regulators against Collusive Behavior. RAND Journal of Economics, 30(2), 232-262.

Laffont, Jean-Jacques, \& Martimort, David. 2002. The Theory of Incentives. Vol. 1. Princeton University Press.

Lazear, Edward P. 2009. Personnel Economics. The MIT Press.

Leaver, Clare. 2009. Bureaucratic Minimal Squawk Behavior: Theory and Evidence from Regulatory Agencies. American Economic Review, 99(3), 572-607. 
Macey, Jonathan R. 1992. Organizational Design and Political Control of Administrative Agencies. Journal of Law, Economics, 83 Organization, 8(1), 93-110.

Makris, Miltiadis. 2009. Incentives for motivated agents under an administrative constraint. Journal of Economic Behavior $\& 3$ Organization, 71(2), 428-440.

Martimort, David. 1996. The Multiprincipal Nature of Government. European Economic Review, 40(3-5), 673-685.

Murdock, Kevin. 2002. Intrinsic Motivation and Optimal Incentive Contracts. RAND Journal of Economics, 33(4), 650-671.

Muris, Timothy J. 2005. Principles for a Successful Competition Agency. University of Chicago Law Review, 72(1), 165-187.

Niskanen, William A. 1968. The Peculiar Economics of Bureaucracy. American Economic Review, 58(2), 293-305.

Niskanen, William A. 2007. Bureaucracy $\&$ Representative Government. Transaction Publishers.

Peltzman, Sam. 1976. Toward a More General Theory of Regulation. Journal of Law and Economics, 19(2), 211-240.

Prendergast, Canice. 1999. The Provision of Incentives in Firms. Journal of Economic Literature, 37(1), 7-63.

Schinkel, Maarten Pieter. 2011. Market Oversight Games. Amsterdam University Press.

Slottje, Daniel J. (ed). 1999. The Role of the Academic Economist in Litigation Support. North Holland.

Tirole, Jean. 1986. Hierarchies and Bureaucracies: On the Role of Collusion in Organizations. Journal of Law, Economics \& Organization, 2, 181.

Vives, Xavier (ed). 2009. Competition Policy in the EU: Fifty Years on from the Treaty of Rome. Oxford University Press.

Wils, Wouter P. J. 2011. Discretion and Prioritisation in Public Antitrust Enforcement, in Particular EU Antitrust Enforcement. World Competition: Law and Economics Review, 34(3), 353-382.

Wilson, James. 1991. Bureaucracy: What Government Agencies Do And Why They Do It. Basic Books. 


\section{Appendix}

\section{Proof of Lemma 1}

The official knows his own talent level $\theta$, the difficulty of all possible tasks $\left\{\psi_{1}, \ldots, \psi_{n}\right\}$, and the contract

offered to him, with rewards for completing each of these tasks $\left\{R_{1}, \ldots, R_{n}\right\}$. If the official chooses to perform task $i$, he has expected utility

$$
U^{O}=p_{i} R_{i}-\frac{1}{2} \gamma a^{2}
$$

where $p_{i}=a \times \theta^{\psi_{i}}$ and $R_{i}$ is the reward offered for completing task $i$. The official determines the effort he will put in by maximizing expected utility

$$
E\left[U^{O}\right]=p_{i} R_{i}-\frac{1}{2} \gamma a^{2}=a \theta^{\psi_{i}} R_{i}-\frac{1}{2} \gamma a^{2},
$$

which leads to first-order condition

$$
\frac{\partial U^{O}}{\partial a}=\theta^{\psi_{i}} R_{i}-\gamma a=0
$$

and so to

$$
a^{*}=\frac{\theta^{\psi_{i}} R_{i}}{\gamma}
$$

which immediately from $p_{i}=a \times \theta^{\psi_{i}}$ gives the probability of tasks' completion under the official's optimal choice of effort as

$$
p_{i}=\frac{\theta^{2 \psi_{i}} R_{i}}{\gamma}
$$

Hence, an official that performs task $i$ and exerts his optimal effort level has expected utility

$$
E\left[U^{O}\right]=a^{*} \theta^{\psi_{i}} R_{i}-\frac{1}{2} \gamma a^{2}=\frac{\theta^{2 \psi_{i}} R_{i}^{2}}{\gamma}-\frac{1}{2} \gamma \frac{\theta^{2 \psi_{i}} R_{i}^{2}}{\gamma^{2}}=\frac{\theta^{2 \psi_{i}} R_{i}^{2}}{2 \gamma}=\frac{\left(\theta^{\psi_{i}} R_{i}\right)^{2}}{2 \gamma}
$$

Maximizing this expression over the set of tasks $i \in\{1, \ldots, n\}$, taking into account the contract offered to the official $\left\{R_{1}, \ldots, R_{n}\right\}$, the official chooses to perform the task for which utility

$$
\theta^{\psi_{i}} R_{i}
$$

attains the highest value. 


\section{Proof of Lemma 2}

The head's utility generated by rewarding a given task $i$ is

$$
U^{H}=p_{i} d_{i}+\phi d_{i}+V\left(B-p_{i} R_{i}\right)=\frac{\theta^{2 \psi_{i}} R_{i} d_{i}}{\gamma}+\phi d_{i}+V\left(B-\frac{\theta^{2 \psi_{i}} R_{i}^{2}}{\gamma}\right) .
$$

The optimal reward $R_{i}$ for task $i$ follows from

$$
\frac{\partial U^{H}}{\partial R_{i}}=\frac{\theta^{2 \psi_{i}} d_{i}}{\gamma}-2 V \frac{\theta^{2 \psi_{i}} R_{i}}{\gamma}=0
$$

as

$$
R_{i}^{u}=\frac{d_{i}}{2 V}
$$

Substituting this optimal reward level back into the head's utility function we get

$$
U^{H}=\frac{\theta^{2 \psi_{i}} d_{i}^{2}}{2 V \gamma}+\phi d_{i}+V\left(B-\frac{\theta^{2 \psi_{i}} d_{i}^{2}}{4 V^{2} \gamma}\right)=\frac{\theta^{2 \psi_{i}} d_{i}^{2}}{4 V \gamma}+\phi d_{i}+V B
$$

Since the fixed component is immaterial for his choices, the task that maximizes the head's utility is the task that maximizes $\frac{\theta^{2 \psi_{i}} d_{i}^{2}}{4 V \gamma}+\phi d_{i}$. The best probability of completing this task is then implied by the reward $R_{i}^{u}=\frac{d_{i}}{2 V}$ and Lemma 1 .

\section{Proof of Proposition 1}

For the two tasks $A$ and $B$ with $\left(d_{B}, \psi_{B}\right)<\left(d_{A}, \psi_{A}\right)$, Lemma 2 implies that $R_{A}^{u}>R_{B}^{u}$. Consider two cases separately: first the case when both the head's most preferred rewards are unaffordable, and second the case in which only $R_{B}^{u}$ is affordable under the budget constraint.

Case 1: Fully binding budget constraint. For the budget values $D<R_{B}^{u}$, none of the $u$-rewards is affordable, and the agency head will just reward his most preferred task by offering the maximal reward $D$ for completion. The head's expected utility generated by the two tasks then amounts to

$$
\begin{aligned}
& E\left[U_{A}^{H}\right]=\frac{\theta^{2 \psi_{A}} D d_{A}}{\gamma}+\phi d_{A}+V\left(D-\frac{\theta^{2 \psi_{A}} D^{2}}{\gamma}\right), \\
& E\left[U_{B}^{H}\right]=\frac{\theta^{2 \psi_{B}} D d_{B}}{\gamma}+\phi d_{B}+V\left(D-\frac{\theta^{2 \psi_{B}} D^{2}}{\gamma}\right) .
\end{aligned}
$$

Task $B$ will be preferred by the agency's head if 


$$
\frac{\theta^{2 \psi_{B}} D d_{B}}{\gamma}+\phi d_{B}+V\left(D-\frac{\theta^{2 \psi_{B}} D^{2}}{\gamma}\right)>\frac{\theta^{2 \psi_{A}} D d_{A}}{\gamma}+\phi d_{A}+V\left(D-\frac{\theta^{2 \psi_{A}} D^{2}}{\gamma}\right)
$$

amounting to

$$
0<\left(\theta^{2 \psi_{A}}-\theta^{2 \psi_{B}}\right) V B^{2}+\left(\theta^{2 \psi_{B}} d_{B}-\theta^{2 \psi_{A}} d_{A}\right) B+\gamma \phi\left(d_{B}-d_{A}\right) .
$$

The roots of the quadratic equation are

$$
\begin{aligned}
& D_{1}^{*}=\frac{\theta^{2 \psi_{B}} d_{B}-\theta^{2 \psi_{A}} d_{A}-\sqrt{\left(\theta^{2 \psi_{B}} d_{B}-\theta^{2 \psi_{A}} d_{A}\right)^{2}-4\left(V \theta^{2 \psi_{A}}-V \theta^{2 \psi_{B}}\right) \gamma \phi\left(d_{B}-d_{A}\right)}}{2 V\left(\theta^{2 \psi_{B}}-\theta^{2 \psi_{A}}\right)} . \\
& D_{2}^{*}=\frac{\theta^{2 \psi_{B}} d_{B}-\theta^{2 \psi_{A}} d_{A}+\sqrt{\left(\theta^{2 \psi_{B}} d_{B}-\theta^{2 \psi_{A}} d_{A}\right)^{2}-4\left(V \theta^{2 \psi_{A}}-V \theta^{2 \psi_{B}}\right) \gamma \phi\left(d_{B}-d_{A}\right)}}{2 V\left(\theta^{2 \psi_{B}}-\theta^{2 \psi_{A}}\right)} .
\end{aligned}
$$

There will be a switch among the performed tasks for these budget values if they fall in the $\left(0, R_{B}^{u}\right)$ interval. Both roots are above 0 if and only if the solution is in real numbers $\left(\left(\theta^{2 \psi_{B}} d_{B}-\theta^{2 \psi_{A}} d_{A}\right)^{2}-\right.$ $\left.4\left(V \theta^{2 \psi_{A}}-V \theta^{2 \psi_{B}}\right) \gamma \phi\left(d_{B}-d_{A}\right)\right)$, and $\theta^{2 \psi_{A}} d_{A}<\theta^{2 \psi_{B}} d_{B}$. The negative root is always below $R_{B}^{u}$. The positive root is below $R_{B}^{u}$ if $0>\left(\theta^{4 \psi_{B}}-\theta^{4 \psi_{A}}\right) d_{B}^{2}-2 d_{B} d_{A}\left(\theta^{2 \psi_{B}+2 \psi_{A}}-\theta^{4 \psi_{A}}\right)-4\left(\theta^{2 \psi_{A}}-\theta^{2 \psi_{B}}\right) V \gamma \phi\left(d_{B}-\right.$ $\left.d_{A}\right)$.

Case 2: Partially binding budget constraint. For the budget values $R_{B}^{u} \leq D \leq R_{A}^{u}$, the optimal affordable reward for task $A$ is $D$, since the head's utility generated by rewarding task $A$ is increasing in the reward offered until $R_{A}^{u}$. $R_{A}^{u}$ is the point above which the marginal benefit of further increasing reward for task $A$ is lower than marginal benefit of keeping the money, $V$. For task $B, R_{B}^{u}$ is still affordable. For the budget values $R_{B}^{u}<D \leq R_{A}^{u}$, the head's expected utilities generated by rewarding the two tasks, given the optimal choices of both the agency's head and the official, are thus

$$
\begin{gathered}
E\left[U_{A}^{H}\right]=\frac{\theta^{2 \psi_{A}} D d_{A}}{\gamma}+\phi d_{A}+V\left(D-\frac{\theta^{2 \psi_{A}} D^{2}}{\gamma}\right), \\
E\left[U_{B}^{H}\right]=\frac{\theta^{2 \psi_{B}} d_{B}^{2}}{4 V \gamma}+\phi d_{B}+V D .
\end{gathered}
$$

Task $B$ will be preferred by the agency's head if

$$
\frac{\theta^{2 \psi_{B}} d_{B}^{2}}{4 V \gamma}+\phi d_{B}+V D>\frac{\theta^{2 \psi_{A}} D d_{A}}{\gamma}+\phi d_{A}+D\left(D-\frac{\theta^{2 \psi_{A}} D^{2}}{\gamma}\right)
$$


amounting to

$$
0<\left(4 V^{2} \theta^{2 \psi_{A}}\right) D^{2}+D\left(-4 V \theta^{2 \psi_{A}} d_{A}\right)+\left(-4 V \gamma \phi d_{A}+\theta^{2 \psi_{i}} d_{B}^{2}+4 V \gamma \phi d_{B}\right)
$$

The roots of the quadratic equation are

$$
D_{1,2}=\frac{\theta^{\psi_{A}} d_{A} \pm \sqrt{\theta^{2 \psi_{A}} d_{A}^{2}+4 V \gamma \phi d_{A}-\theta^{2 \psi_{B}} d_{B}^{2}-4 V \gamma \phi d_{B}}}{2 V \theta^{\psi_{A}}} .
$$

The positive root never falls within the interval $\left(R_{B}^{u}, R_{A}^{u}\right)$. The negative root falls within $\left(R_{B}^{u}, R_{A}^{u}\right)$ if and only if $4 V \gamma \phi\left(d_{A}-d_{B}\right)<d_{B}^{2}\left(\theta^{2 \psi_{A}}+\theta^{2 \psi_{B}}\right)-2 \theta^{2 \psi_{A}} d_{A} d_{B}$. If this condition is satisfied, then there is a point in the interval $D \in\left(R_{B}^{u}, R_{A}^{u}\right)$, where the agency head is indifferent between offering $D$ as a reward for task $A$, and offering $R_{B}^{u}$ as a reward for task $B$. For the solution to exist in real numbers, it is required that $\theta^{2 \psi_{A}} d_{A}^{2}+4 V \gamma \phi d_{A}-\theta^{2 \psi_{B}} d_{B}^{2}-4 V \gamma \phi d_{B}>0$, after rewriting

$$
\frac{\theta^{2 \psi_{A}} d_{A}^{2}}{4 V \gamma}+\phi d_{A}>\frac{\theta^{2 \psi_{B}} d_{B}^{2}}{4 V \gamma}+\phi d_{B}
$$

which implies by Lemma 2 that task $A$ is selected by the agency's head when the budget is not binding $\left(D>R_{A}^{u}\right)$, and the agency switches to performing task $B$ below the budget value

$$
D_{2}^{*}=\frac{\theta^{\psi_{A}} d_{A}-\sqrt{\theta^{2 \psi_{A}} d_{A}^{2}+4 V \gamma \phi d_{A}-\theta^{2 \psi_{B}} d_{B}^{2}-4 V \gamma \phi d_{B}}}{2 V \theta^{\psi_{A}}}
$$

as long as it falls within the interval $\left(R_{B}^{u}, R_{A}^{u}\right)$, which in turn is ensured by the condition

$$
4 V \gamma \phi\left(d_{A}-d_{B}\right)<d_{B}^{2}\left(\theta^{2 \psi_{A}}+\theta^{2 \psi_{B}}\right)-2 \theta^{2 \psi_{A}} d_{A} d_{B}
$$

To sum up the proof, if the root $D_{1}^{*}$ exists satisfying all the above conditions ${ }^{45}$, one of two scenarios is possible. First, task $B$ is the head's most preferred task when the budget is non-binding. Then task $B$ is performed above $D_{1}^{*}$, and task $A$ below. Second, task $A$ is the head's most preferred task when the budget is non-binding. Then there exists a $D_{2}^{*}$ on one of the intervals $D \in\left(R_{B}^{u}, R_{A}^{u}\right)$ or $D \in\left(0, R_{B}^{u}\right)$, such that task $A$ is performed on intervals $D \in\left(0, D_{1}^{*}\right)$ and $D \in\left(D_{2}^{*}, \infty\right)$, and task $B$ on the interval $D \in\left(D_{1}^{*}, D_{2}^{*}\right)$. If $D_{1}^{*}$ does not exist, task $A$ is performed for all values of the budget constraint $D$.

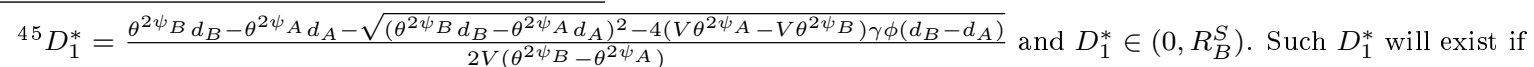
$\left(\theta^{2 \psi_{B}} d_{B}-\theta^{2 \psi_{A}} d_{A}\right)^{2}-4\left(V \theta^{2 \psi_{A}}-V \theta^{2 \psi_{B}}\right) \gamma \phi\left(d_{B}-d_{A}\right)$ and $\theta^{2 \psi_{A}} d_{A}<\theta^{2 \psi_{B}} d_{B}$.
} 


\section{Proof of Proposition 2}

For the two tasks $A$ and $B$ with $\left(d_{B}, \psi_{B}\right)<\left(d_{A}, \psi_{A}\right)$, when the official performs task $i$, social welfare is

$$
E[W]=p_{i} d_{i}-D=a \theta^{\psi_{i}} d_{i}-D=\frac{\theta^{\psi_{i}} R_{i}}{\gamma} \theta^{\psi_{i}} d_{i}-D
$$

which without a binding discretionary budget, when $R_{i}=R_{i}^{u}=\frac{d_{i}}{2 V}$, is

$$
E[W]=\frac{\theta^{\psi_{i}} R_{i}}{\gamma} \theta^{\psi_{i}} d_{i}-D=\frac{\theta^{\psi_{i}} d_{i}}{2 V \gamma} \theta^{\psi_{i}} d_{i}-D=\frac{\theta^{2 \psi_{i}} d_{i}^{2}}{2 V \gamma}-D
$$

Society therefore prefers that the official performs the task that has maximal $\theta^{\psi_{i}} d_{i}$, hence the agency head's interests are aligning with those of society only when $\phi=0$. However, society would prefer to always pay the full $D$ instead of $R_{i}^{u}$, given that $D$ is already determined and any residue is lost.

To see the effect of a binding budget, first consider the case in which both the head's most preferred rewards are unaffordable, and second the case when only $R_{B}^{u}$ is affordable under the budget constraint.

Case 1: Fully binding budget constraint. When $D$ is fully binding, $R_{i}=D$, or equivalently $D<R_{i}^{u}$ for the least rewarding task $i$. Welfare is given as

$$
E[W]=p_{i} d_{i}-B=a \theta^{\psi_{i}} d_{i}-D=\frac{\theta^{\psi_{i}} R_{i}}{\gamma} \theta^{\psi_{i}} d_{i}-D=\frac{\theta^{2 \psi_{i}} D}{\gamma} d_{i}-D
$$

To evaluate the welfare effect of the jump under the head's choices of contract, rewrite

$$
W=\frac{\theta^{2 \psi_{i}} D}{\gamma} d_{i}-D=D\left(\frac{\theta^{2 \psi_{i}} d_{i}}{\gamma}-1\right)
$$

The jump at a point $D^{*}$ between tasks $A$ and $B$ amounts to the welfare difference

$$
\Delta W_{A, B}=D^{*}\left(\frac{\theta^{2 \psi_{A}} d_{A}}{\gamma}-1\right)-D^{*}\left(\frac{\theta^{2 \psi_{B}} d_{B}}{\gamma}-1\right)=D^{*} \frac{\theta^{2 \psi_{A}} d_{A}-\theta^{2 \psi_{B}} d_{B}}{\gamma} .
$$

Note that the sign of the welfare effect of the jump is independent of the value $D^{*}$. From Proposition 2 , we know that a necessary condition for $D_{2}^{*}$ to exist is $\theta^{2 \psi_{A}} d_{A}<\theta^{2 \psi_{B}} d_{B}$. When the budget drops below $D_{2}^{*}$, social welfare increases. When the budget drops below $D_{1}^{*}$, social welfare decreases. Society prefers a performance of task $B$ when the budget is fully binding, while the agency's head prefers task $B$ for at least some fully binding budget values. This is due to the fact that society's preference between tasks never changes for fully binding budget values, as it prefers the task with the highest value for

$$
\theta^{2 \psi_{i}} d_{i}
$$


Notice the power 2, which is the key difference from the nonbinding budget situation. Also note the difference from the task that the agency head chooses - the task with maximal $\theta^{2 \psi_{i}} B\left(d_{i}-B V\right)$ as long as $\phi=0$. If $V \rightarrow 0$, society's and the head's preferences are aligned as far as the task selection goes, and the task with the highest $\theta^{2 \psi_{i}} d_{i}$ is always performed on the interval $D \in\left(0, R_{B}^{S}\right)$. Furthermore, the expression $\Delta W_{A, B}$ will be zero if the public evaluates task $B$ as

$$
d_{B}^{S W}=d_{A} \theta^{2\left(\psi_{A}-\psi_{B}\right)},
$$

instead of $d_{B}^{S W F}=d_{B}$. This is also the value for which the head's choice of $D_{2}^{*}$ is zero, i.e. full alignment of society and head with no resources. Higher or lower value assigned to this task's completion by society then amounts to positive/negative jump in welfare. $D_{2}^{*}$ then co-determines the size of the jump. Analogically, we can rewrite the zero-jump condition in terms of society's evaluation $d_{A}^{S W}$.

Case 2: Partially binding budget constraint. With a partially binding budget, i.e. $R_{A}^{u} \geq$ $D \geq R_{B}^{u}$, the head offers $D$ as a reward for completing task $A$, and $R_{B}^{S}$ for task $B$. Social welfare generated by the performance of the two tasks is then given by

$$
\begin{aligned}
& E\left[W_{A}\right]=p_{A} d_{A}-D=a \theta^{\psi_{A}} d_{A}-D=\frac{\theta^{\psi_{A}} R_{A}}{\gamma} \theta^{\psi_{A}} d_{A}-D=\frac{\theta^{2 \psi_{A}} D}{\gamma} d_{A}-D, \\
& E\left[W_{B}\right]=p_{B} d_{B}-D=a \theta^{\psi_{B}} d_{B}-D=\frac{\theta^{\psi_{B}} R_{B}}{\gamma} \theta^{\psi_{B}} d_{B}-D=\frac{\theta^{2 \psi_{B}} d_{B}^{2}}{2 V \gamma}-D .
\end{aligned}
$$

Note that $D_{1}^{*}$ cannot occur on this interval as shown in Proposition 2. The jump at a point $D_{2}^{*}$ between tasks $A$ and $B$ amounts to welfare difference

$$
\begin{aligned}
\Delta W_{A, B}= & \frac{\theta^{2 \psi_{A}} D_{2}^{*}}{\gamma} d_{A}-D_{2}^{*}-\frac{\theta^{2 \psi_{B}} d_{B}^{2}}{2 V \gamma}+D_{2}^{*} \\
& =\frac{\theta^{2 \psi_{A}} d_{A}}{\gamma} D_{2}^{*}-\frac{\theta^{2 \psi_{B}} d_{B}^{2}}{2 V \gamma} .
\end{aligned}
$$

Although this condition is no longer as clear-cut as for the fully binding budget constraint, the partially binding range for $D_{2}^{*}$ and condition for its existence ensure that $\frac{\theta^{2 \psi_{A}} d_{A}}{\gamma} D_{2}^{*}<\frac{\theta^{2 \psi_{B}} d_{B}^{2}}{2 V \gamma}$, and the public prefers task $B$ over task $A$ at the point $D_{2}^{*}$, where the agency's head is indifferent between the two, due to head's extra benefits from task $A$ stemming from $V$ and $\phi$. Finally, $\Delta W_{A, B}$ will be zero if society evaluates the benefits from completing task $B$ as

$$
d_{B}^{S W}=\sqrt{2 V \theta^{2 \psi_{A}-2 \psi_{B}} d_{A} D_{2}^{*}},
$$


where $D_{2}^{*}=\frac{\theta^{\psi} A_{A}-\sqrt{\theta^{2 \psi} A d_{A}^{2}+4 V \gamma \phi d_{A}-\theta^{2 \psi_{B}} d_{B}^{2}-4 V \gamma \phi d_{B}}}{2 V \theta^{\psi} A}$ and $d_{B}$ is the head's valuation of the simpler task's benefits. 